\title{
The Unexpected Role for the Aryl Hydrocarbon Receptor on Susceptibility to Experimental Toxoplasmosis
}

\author{
Yuriko Sanchez, ${ }^{1}$ Juan de Dios Rosado, ${ }^{1}$ Libia Vega, ${ }^{2}$ Guillermo Elizondo, ${ }^{3}$ \\ Elizabeth Estrada-Muñiz, ${ }^{2}$ Rafael Saavedra, ${ }^{4}$ Imelda Juárez, ${ }^{1}$ and Miriam Rodríguez-Sosa ${ }^{1}$ \\ ${ }^{1}$ Unidad de Biomedicina, Facultad de Estudios Superiores-Iztacala, Universidad Nacional Autónoma de México (UNAM), \\ CP 54090, o. Tlalnepantla, Edo. de México, Mexico \\ ${ }^{2}$ Departamento de Toxicología, Centro de Investigación y Estudios Avanzados-IPN, Avenue IPN 2508, San Pedro Zacatenco, \\ CP 07360 México, DF, Mexico \\ ${ }^{3}$ Departamento de Biología Celular, Centro de Investigación y Estudios Avanzados-IPN, Avenue IPN 2508, \\ San Pedro Zacatenco, CP 07360 México, DF, Mexico \\ ${ }^{4}$ Depertamento de inmunología, Instituto de Investigaciones Biomédicas, UNAM, México, DF, Mexico
}

Correspondence should be addressed to Miriam Rodríguez-Sosa, rodriguezm@campus.iztacala.unam.mx

Received 20 August 2009; Accepted 15 October 2009

Academic Editor: Luis I. Terrazas

Copyright ( $\odot 2010$ Yuriko Sanchez et al. This is an open access article distributed under the Creative Commons Attribution License, which permits unrestricted use, distribution, and reproduction in any medium, provided the original work is properly cited.

\begin{abstract}
The aryl hydrocarbon receptor (AhR) is part of a signaling system that is mainly triggered by xenobiotic agents. Increasing evidence suggests that AhR may regulate immunity to infections. To determine the role of AhR in the outcome of toxoplasmosis, we used AhR-/- and wild-type (WT) mice. Following an intraperitoneal infection with Toxoplasma gondii (T. gondii), AhR-/- mice succumbed significantly faster than WT mice and displayed greater liver damage as well as higher serum levels of tumor necrosis factor (TNF)- $\alpha$, nitric oxide (NO), and IgE but lower IL-10 secretion. Interestingly, lower numbers of cysts were found in their brains. Increased mortality was associated with reduced expression of GATA-3, IL-10, and 5-LOX mRNA in spleen cells but higher expression of IFN- $\gamma$ mRNA. Additionally, peritoneal exudate cells from AhR-/- mice produced higher levels of IL-12 and IFN- $\gamma$ but lower TLR2 expression than WT mice. These findings suggest a role for AhR in limiting the inflammatory response during toxoplasmosis.
\end{abstract}

\section{Introduction}

Aryl hydrocarbon receptor (AhR) is a ligand-activated transcription factor [1]. Together with its transcriptional regulators, basic helix-loop-helix Per-Arnt-Sim (bHLH-PAS) nuclear partner, and aryl hydrocarbon receptor nuclear transporter (ARNT), it provides a powerful signaling system during a critical response to several environmental pollutants such as polyhalogenated aromatic and polyaromatic hydrocarbons [2]. The AhR function is particularly wellcharacterized in response to the exogenous compound 2,3,7,8-tetrachlorodibenzo-p-dioxin (TCDD) [3]. Moreover, several lines of evidence suggest that a battery of proinflammatory cytokine genes can be upregulated upon interaction of TCDD with AhR. TCDD treatment causes increased expression of tumor necrosis factor (TNF)- $\alpha$, interleukin
(IL)-1, IL-2, interferon (IFN)- $\gamma$, IL-18, IL-6, Chemokine (C-C motif) ligand 1 (CCL1), and plasminogen activator inhibitor-2 (PAI-2) [4-9]. Additionally, Negishi et al. demonstrated that a synthetic antiallergic agent M50354, which is another AhR agonist, increased the levels of IFN$\gamma$ associated with reduced expression of GATA-3, a key factor for Th2 differentiation [10].

In addition to its role in metabolizing exogenous compounds as part of an adaptive chemical response, there is growing evidence suggesting that AhR has normal physiological functions and that it likely has endogenous ligands. For example, there is evidence for the importance of AhR in normal development, liver functions, circadian rhythm, response to hypoxia, hormone signaling, and vascular regulation [11-14]. We previously reported that spleen cells from AhR-null mice overproduce IFN- $\gamma$ and 
IL-12 when challenged with concanavalin-A (ConA) or restimulated with ovalbumin in vitro [15]. This observation agrees with previous findings indicating that AhR plays an important role in normal development and function of the immune system [16]. Moreover, recently are emerging new evidences that AhR also plays a role in normal physiology, including certain immune responses [17]. In particular, Th17 cells and dendritic cells (DCs) express high levels of AhR $[18,19]$.

AhR has been implicated in the response to different infectious agents. For example, in influenza virus infection TCDD-induced AhR-activation diminishes the memory response but does not impair host resistance [20]. In lethal Streptococcus pneumonia infection model, the survival rate is slightly enhanced in mice lacking AhR [21]. AhR-/mice infected with Listeria monocytogenes, an intracellular bacteria, are more susceptible to infection but develop enhanced resistance to reinfection [22], even though their serum levels of inflammatory cytokines such as IL-6, IFN$\gamma$, and TNF- $\alpha$ are comparable to WT mice. Additionally, macrophages from AhR-/- mice retain their ability to ingest Listeria and inhibit parasite growth [22]. These data suggest that AhR contributes to an optimal immune response, but its function appears to be distinct depending on the pathogen. Thus, establishment of the role of AhR in some parasitic infections may extend our understanding of the biological functions of AhR.

Toxoplasma gondii is an opportunistic protozoan parasite that causes toxoplasmosis, which is clinically asymptomatic in most individuals but can be fatal in immunocompromised hosts. Immunity to $T$. gondii is highly dependent on cellmediated effector responses, that consist of high levels of type 1 cytokine production [23-26]. The IL-12/IFN- $\gamma$ immune response axis plays a crucial role in determining resistance to T. gondii infection. Deficiencies in IFN- $\gamma$ production, IFN- $\gamma$ receptor-mediated signaling pathway, cells that produce IFN$\gamma$ such as natural killer (NK) cells [27], $\mathrm{CD}^{+}$and $\mathrm{CD} 8^{+}$ $\mathrm{T}$ cells [28], macrophage migration inhibitory factor (MIF) [29], or some other effector molecules such as nitric oxide (NO) [30], result in increased susceptibility to T. gondii. Furthermore, deficiencies in IL-12 [31], its receptor, or its intracellular signaling pathway (STAT-4) [32] render mice extremely susceptible to acute toxoplasmosis with survival rates similar to those observed in IFN- $\gamma$-deficient animals. On the other hand, exacerbated proinflammatory response can lead to immunopathology and death [33]. For this reason the immune system has evolved an elaborated series of pathways to downregulate proinflammatory responses. Since previous reports suggest that AhR participates in modulating Th1/Th2 balance and proinflammatory responses [10, 15], we analyzed the role of AhR in host control of experimental toxoplasmosis. We showed that AhR-/- mice infected with ME49 strain of T. gondii develop fewer cysts in the brain but, paradoxically, succumb significantly faster than WT mice. The increased mortality rate of AhR-/- mice upon T. gondii infection was associated with higher levels of TNF- $\alpha$ and IFN$\gamma$ and lower levels of IL-10 and GATA-3. These findings indicate that AhR plays an important role in downregulating inflammatory responses during Toxoplasma gondii infection.

\section{Material and Methods}

2.1. Mice. AhR-deficient (AhR-/-) and WT $(\mathrm{AhR}+/+)$ mice were generated as previously described $[15,16]$. These mice lack a functional AhR, as the exon1 is replaced from the translational start site onwards with a neomycin gene. AhR-/mice were backcrossed with the C57BL/6 strain for at least 10 generations. AhR-/- mice were maintained as heterozygotes $(\mathrm{AhR}+/-)$ in our laboratory. AhR+/- males were matted with AhR+/- females to generate WT, AhR+/-, and AhR-/mice. In the following experiments, we used eight- to 10week-old male WT and homozygous mutant littermate mice (AhR-/-). All of the mice were maintained in a pathogenfree environment at Centro de Investigación y Estudios Avanzados del Instituto Politécnico Nacional animal facility in accordance with institutional and national guidelines for animal research.

2.2. Parasite and Experimental Infections. Cysts from the avirulent ME49 strain were harvested from the brains of C57BL/6 mice that had been inoculated intraperitoneally (i.p.) with 20 cysts, 1 to 2 months before harvest. For experimental infections, brain suspensions were adjusted to 40 cysts per $200 \mu \mathrm{L}$ in PBS. WT and AhR-/- mice received either 40 ME49 cysts or PBS via i.p. Control inoculations with uninfected brain suspensions failed to elicit detectable inflammatory responses or significant increase in cytokine levels. Soluble Toxoplasma antigen (STAg) from tachyzoites of T. gondii was prepared as described previously [34].

2.3. Quantification of Cysts in the Brain. To assess the disease progression, brains from T. gondii-infected WT and AhR/ - animals were removed aseptically and homogenized in $2 \mathrm{~mL}$ of PBS at days $10,15,25,57$, and 60 postinfection. The total number of cysts was determined by examination under the microscope. The cysts were counted in a $10 \mu \mathrm{L}$ brain-suspension at least three times, and the averages were multiplied by 200. Parallel semiquantification of parasitespecific DNA sequences was performed on the same brain samples in order to confirm the microscopic findings, as described previously [15]. In brief, brains from T. gondiiinfected animals were collected at day 40 post infection. DNA was extracted from tissues using the Qiamp tissue kit (Qiagen, Chatswort, CA, USA), and 50 and $25 \mathrm{ng}$ of each sample was analyzed by polymerase chain reaction (PCR). PCR amplification was performed on parasite DNA to amplify a 200 - to 300 -fold repeated fragment of $529 \mathrm{bp}$ (primers TOX4, 5'-CGCTGCAGGGAGGAAGACGAAAGTTG- $3^{\prime}$ and TOX, $5^{\prime}$-CGCTGCAGACACAGTGCATCTGGATT- $\left.3^{\prime}\right)$. The $529 \mathrm{bp}$ fragment was found in all 60 strains of T. gondii tested. This fragment is unique to T. gondii DNA and is distinct from that of other parasites [35]. The mouse GAPDH gene (primers, Table 1) was amplified in parallel as a control to monitor PCR inhibition and to control for DNA integrity.

2.4. Cell Preparations and Culture Conditions. Twenty-five days after T. gondii infection Peritoneal Exudate Cells (PECs) 
TABLE 1: Oligonucleotide primers used for gene expression analysis by RT-PCR.

\begin{tabular}{|c|c|c|c|c|c|}
\hline Target & Primer sequence $\left(5^{\prime}-3^{\prime} \text { direction }\right)^{\mathrm{a}}$ & Product size (bp) & Cycles & Alignment $\left({ }^{\circ} \mathrm{C}\right)$ & Reference \\
\hline \multirow{2}{*}{ IFN- $\gamma$} & F-AGCGGCTGACTGAACTCAGATTGTAG & \multirow{2}{*}{243} & \multirow{2}{*}{30} & \multirow{2}{*}{57} & \\
\hline & R-GTCACAGTTTTCGCTGTATAGGG & & & & [36] \\
\hline \multirow{2}{*}{ IL-10 } & F-ACCTGGTAGAAGTGATGCCCCAGGCA & \multirow{2}{*}{237} & \multirow{2}{*}{30} & \multirow{2}{*}{56} & \\
\hline & R-CTATGCAGTTGATGAAGATGTCAAA & & & & [37] \\
\hline \multirow{2}{*}{ GATA-3 } & F-GAAGGCATCCAGACCCGAAAC & \multirow{2}{*}{255} & \multirow{2}{*}{30} & \multirow{2}{*}{56} & \\
\hline & R-ACCCATGGCGGTGACCATGC & & & & [38] \\
\hline \multirow{2}{*}{ 5-LOX } & F-ATTGTTCCCATTGCCATCCAGCTCA & \multirow{2}{*}{529} & \multirow{2}{*}{30} & \multirow{2}{*}{56} & \\
\hline & R-TCGTTCTCATAGTAGATGCTCACCA & & & & [39] \\
\hline \multirow[t]{2}{*}{ GAPDH } & F-CTCATGACACAGTCCATGC & \multirow{2}{*}{201} & \multirow[t]{2}{*}{30} & \multirow{2}{*}{54} & \\
\hline & R-CACATTGGGGGTAGGAACAC & & & & [40] \\
\hline
\end{tabular}

${ }^{a} \mathrm{~F}$ : forward primer; R: reverse primer

and spleen cells were obtained from WT and AhR-/- T. gondii infected mice, in sterile conditions, and cultured as previously described [41]. In brief, spleen tissues were minced and filtered to obtain spleen cells, which were then washed and resuspended in DMEM culture medium supplemented with $10 \%$ Fetal Calf Serum (FCS), $2 \mathrm{mM}$ L-glutamine, $0.25 \mathrm{U} / \mathrm{mL}$ penicillin, and $100 \mathrm{mg} / \mathrm{mL}$ streptomycin (all from GIBCO, BRL Grand Island, NY, USA). Splenocytes were resuspended at $5 \times 10^{6}$ cells $/ \mathrm{mL}$ in the same medium. One hundred $\mu \mathrm{L}$ of the cell suspensions were transferred to 96-well flat bottom culture plates (Costar, Cambridge,MA, USA) and stimulated with either $100 \mu \mathrm{L}$ of Con-A mitogen solution $(2 \mu \mathrm{g} / \mathrm{mL}$; Sigma, St. Louis, MO, USA) or with soluble Toxoplasma antigen (STAg) $(2.5 \mu \mathrm{g} / \mathrm{mL})$. Plates were then incubated at $37^{\circ} \mathrm{C}, 5 \% \mathrm{CO}_{2}$ for 72 hours or 6 days with Con-A or STAg, respectively. Fifty-four hours after seeding the plates stimulated with STAg, $0.5 \mu \mathrm{Ci}$ of methyl ${ }^{3} \mathrm{H}$-TdR (specific activity $925 \mathrm{GBg} / \mathrm{mmol}$. Amersham, UK) was added to each well. Cells were harvested, pipetted onto a glass fiber filter paper (Wallac), and analyzed by a liquid scintillation counter (Betaplate, Walac).

PECs were prepared as previously described [41]. In brief, $1 \times 10^{6}$ PECs were plated in 24-well plates. Two hours later nonadherent cells were washed-off twice with complete DMEM, and the remaining adherent macrophages $(M \varphi)$ were replenished with complete medium. STAg was added at a final concentration of $2.5 \mu \mathrm{g} / \mathrm{mL}$ for 24 hours. In both spleen and PEC cultures, supernatants were collected, centrifuged, aliquoted, and frozen at $-20^{\circ} \mathrm{C}$ until use.

2.5. Cytokine Measurement. After T. gondii infection, WT and AhR-/- mice were bled from tail snips at various time points. Sera from blood samples and supernatants from cell cultures described above were analyzed to measure production of IL-2, IL-4, IL-10, IL-12p70, IFN- $\gamma$, and TNF$\alpha$ by ELISA (Peprotech, Mexico) using paired monoclonal antibodies and murine recombinant cytokines to make standard curves, as previously described [42]. Optical density (OD) was measured after 5 minutes using an ELISA microplate reader (SpectraMax 250, Molecular Devices, USA) at $405 \mathrm{~nm}$.
2.6. Nitric Oxide Quantification. Nitric oxide (NO) levels in the serum were determined indirectly by measuring the total serum nitrite $\left(\mathrm{NO}_{2-}\right)$ after reduction of nitrate $\left(\mathrm{NO}_{3-}\right)$ to nitrite $\left(\mathrm{NO}_{2-}\right)$ with nitrate reductase following the protocol described by Granger et al. [43] and adapting it to microwell plates (Costar). Briefly, $50 \mu \mathrm{L}$ of serum was incubated at room temperature with $50 \mu \mathrm{L}$ of substrate buffer (imidazole $0.1 \mathrm{~mol} / \mathrm{L}$, NADPH $210 \mu \mathrm{mol} / \mathrm{L}$, flavine adenine dinucleotide $3.8 \mu \mathrm{mol} / \mathrm{L}: \mathrm{pH}$ 7.6, all from Sigma-Aldrich) containing nitrate reductase (Aspergillus niger, Sigma) for 45 minutes to convert $\mathrm{NO}_{3-}$ to $\mathrm{NO}_{2-}$. Total nitrite was then mixed with an equal volume of Griess reagent (1.5\% sulfanilamide, $0.1 \%$ naphthylethylenediamine dihydrochloride, $2.5 \%$ phosphoric acid; all from Sigma) [44], incubated for 10 minutes at room temperature in the dark, and the absorbance was measured at $570 \mathrm{~nm}$ in an automatic microplate reader (Organon Technika Microwell System).Values were quantified using serial dilutions of sodium nitrite.

2.7. Total IgE Determination. Peripheral blood was collected at various time points from tail snips of all experimental mice infected with T. gondii. Blood was centrifuged and stored at $-20^{\circ} \mathrm{C}$ until use. Total IgE production was measured by ELISA, using a commercial kit (Opt-EIA ELISA-set, BDPharmingen).

2.8. Transaminase Enzyme Determination. The presence of the liver transaminase enzymes alanine aminotransferase (ALT) and aspartate aminotransferase (AST) was evaluated in sera from WT and AhR-/- mice at 0, 3, 6, 14, and 25 days after T. gondii infection using ALT and AST kits (Spinreact, S. A. Ctra. Santa Coloma, Spain).

2.9. RT-PCR Assay to Evaluate IFN- $\gamma, I L-10$, and GATA-3 Gene Expression in Spleen Cells and Brains. At 25 days after T. gondii infection (when $40 \%$ the AhR-/- mice die), the brains were removed and total RNA was extracted using TRIzol reagent according to the manufacturer's instructions (Invitrogen, Carlsbad, CA). cDNA synthesis was performed with SuperScript One-Step reverse transcription-PCR (RTPCR, Invitrogen). In brief, $3 \mu \mathrm{g}$ of total RNA was mixed 
with $0.5 \mu \mathrm{g}$ oligo (dT) 12 to -18 primers, $10 \mathrm{mM}$ of each dNTP and $1 \mathrm{X}$ reaction buffer in a final volume of $20 \mu \mathrm{L}$. cDNA reactions were incubated at $65^{\circ} \mathrm{C}$ for 10 minutes to denature the RNA template and quench-cooled for 1 minute. $0.5 \mu \mathrm{L}$ of SSII-RT reverse transcriptase was added, incubated at $42^{\circ} \mathrm{C}$ for 50 minutes and $70^{\circ} \mathrm{C}$ for 15 minutes. $0.5 \mu \mathrm{L}$ of $\mathrm{RNaseH}$ was added and further incubated for 15 minutes at $36^{\circ} \mathrm{C}$. cDNA samples were amplified for to 30 cycles using the Red Taq polymerase (Invitrogen) and specific primers (Table 1). After amplification, PCR products were separated by gel electrophoresis on $1.5 \%$ agarose gels containing SYBR green I, a nucleic acid gel stain used at 1,000X (Amresco), and visualized with the FLA-5000 chemiluminescence detection system (Fujifilm). The data were normalized to glyceraldehyde-3-phosphate dehydrogenase (GAPDH) and analyzed using the MultiGauge Image program. All reactions were repeated three times to ensure reproducibility.

2.10. Histopathology. Livers were removed and fixed in a solution that contained $10 \%$ formalin, $70 \%$ ethanol, and $5 \%$ acetic acid, embedded in paraffin blocks (all from Sigma-Aldrich). Sagittal sections of livers ( $5 \mu \mathrm{m}$ thick) were obtained and mounted on slides and subsequently stained with hematoxylin and eosin (Sigma-Aldrich). Photomicrographs of representative sections were taken with an AxionStar microscope equipped with a built-in digital camera (ZEISS).

2.11. Flow Cytometry Analysis. Fluorescence-activated cells sorting (FACS) analysis on CD4+ T cells, CD8+ T cells, and Treg cells in the spleen and TLR-2+ and CCR5+ macrophages $(\mathrm{M} \varphi)$ from WT and AhR-/- T. gondii-infected mice was performed. Briefly, at 25 days after T. gondii infection, spleen cells or peritoneal adherent $M \varphi$ were stimulated in vitro for 6 days or 24 hours with $2.5 \mu \mathrm{g} / \mathrm{mL}$ of STAg. The spleen cells were stained with fluorescein isothiocyanated (FITC) antiCD8 antibody and phycoerythrinn (PE) anti-CD4 antibody, and Treg cells were stained using a staining kit (Mouse Treg Flow kit) containing FITC anti-CD4 antibody, PE anti-CD25 antibody, and ALEXA anti-Foxp3 antibody, according to the manufacturer's instructions. The $M \varphi$ were stained with FITC anti-F4/80 antibody and PE anti-TLR2 or PE antiCCR5 antibody. The cells were fixed, and the proportion of cells staining positive for the appropriate markers was evaluated (10,000 events/sample) using a flow cytometer (FACS, Becton Dickinson, USA). Nonspecific binding was blocked with FcBlock, and the isotype controls were stained with rat antimouse IgG conjugated with -FITC, -PE, or ALEXA (all from Biolegend, San Diego, CA).

2.12. Statistical Analysis. All statistical analyses were performed using Prism 4 (GaphPad Software, San Diego, CA). Comparisons between WT and AhR-/- animal groups were made using a nonparametric Mann-Whitney's $U$-test and Student's $t$-test as appropriate. For survival assays, logrank test was used. Differences were considered statistically significant when $P$ value was less than .05 .

\section{Results}

3.1. Wild Type and AhR-/- Mice Exhibit Differential Resistance to Toxoplasmosis. To analyze the importance of AhR during acute toxoplasmosis, we first determined whether WT and knockout (AhR-/-) mice differed in their resistance to ME49 T. gondii infection. WT and AhR-/- littermates were challenged i.p. with 40 cysts of $T$. gondii parasites, and we examined the course of the infection for 60 days. As shown in Figure 1(a), AhR-/- mice rapidly showed clinical signs of the disease that sustained for 5 days, while WT mice showed few symptoms. By day 7 after infection, AhR/- mice started to lose weight (Figure 1(b)) and showed piloerection and prostrated behavior. T. gondii-infected AhR/- mice succumbed as early as day 11 after infection and reached $89 \%$ mortality rate by day 60 after infection. In contrast, the mortality rate in WT mice was significantly lower, $6.7 \%$ (Figure 1(c)). Interestingly, despite the evident signs of sickness and death in AhR-/- mice, they developed fewer brain cysts compared to WT mice, even at day 60 postinfection (Figure $2(\mathrm{a}), P<.05)$.

To further confirm our microscopic findings, we quantified the level of $T$. gondii-specific DNA in the brains from both groups of mice at day 25 post infection using semiquantitative PCR based on the 529 bp repeat element (REP; 200 to 300 copies/genome), as reported elsewhere [35]. The level of parasite DNA in the brains of infected WT and AhR-/- mice correlated with the number of cysts, confirming fewer parasite burdens in the brains of AhR-/- mice (Figures 2(b) and 2(c)). Taken together, these data suggest that AhR is critical in the host defense against $T$. gondii infection, and that the increased mortality rate in AhR-/- mice is not due to an inability to restrict parasite replication.

3.2. AhR-/- Mice Develop Significant Reduction of IL-10 and Increase of TNF- $\alpha$ in Sera. Next, we compared the levels of cytokines (IL-12, IFN- $\gamma$, TNF- $\alpha$, and IL-10), nitric oxide (NO), and IgE, in sera from WT and AhR-/- mice after T. gondii infection. No significant differences between AhR/- and WT mice in serum IL-12 and IFN- $\gamma$ levels were detected at any of the time-points examined (Figures 3(a) and 3(b), resp.). However, significantly higher level of the inflammatory cytokine TNF- $\alpha$ was detected after 30 days of infection in sera from AhR-/- mice compared to WT mice (Figure 3(c), $P<.05$ ). This observation was in accordance with a low level of IL-10 observed after 15 days of infection in AhR-/- mice (Figure 3(d), $P<.05$ ). A higher level of total IgE was also observed after 6 days of infection in AhR-/- mice (Figure 3(f), $P<.05)$. Interestingly, the serum nitric oxide level was higher in AhR-/- mice than WT mice on day 25 post infection alone.

3.3. Defective Proliferation and IL-2 Production by AhR-/Spleen Cells. We next determined the functional capacity of spleen cells from both AhR-/- and WT mice to respond to T. gondii-specific stimulation. At day 25 post infection, proliferation of spleen cells from infected AhR-/- or WT mice in the presence of STAg or medium for 5 days was assayed 


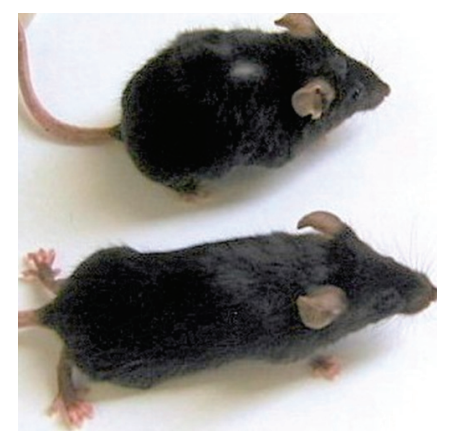

(a)

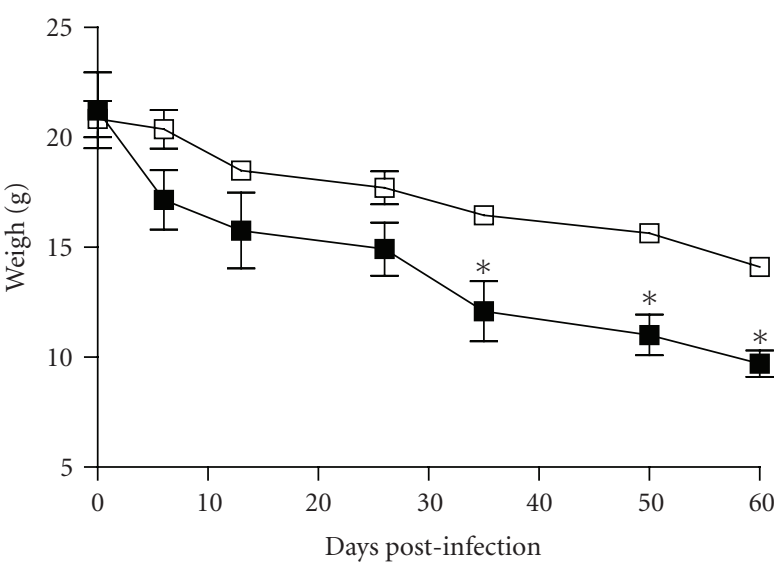

$\square$ WT

AhR-/-

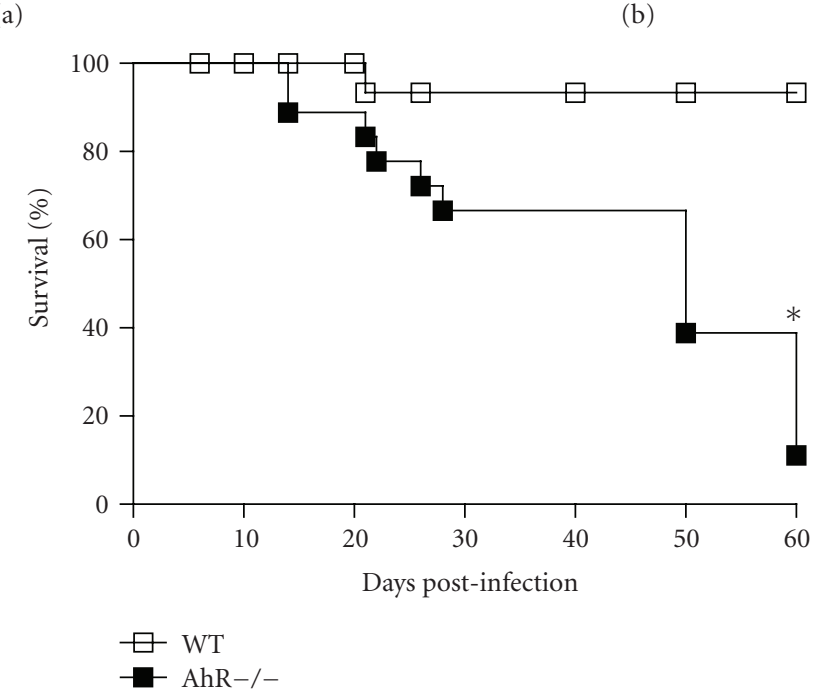

(c)

Figure 1: AhR-/- mice infected with T. gondii display profound weight loss and accelerated mortality compared to infected-wild type mice. Physical appearance (a), body weight (b), and survival rate (c) of AhR-/- and WT mice infected with 40 cysts of T. gondii were monitored during the times indicated. The values presented are the mean \pm SD of at least 6 animals per time point per group. The experiment shown is representative of at least four performed that gave similar results. ${ }^{*} P<.05$ for body weight by student's $t$-test; ${ }^{*} P<.0001$ for survival rate by log-rank test between the means of the values obtained with AhR-/- versus wild-type control mice.

by $[3 \mathrm{H}]$ thymidine incorporation. As shown in Figure 4(a), only primed-WT spleen cells were able to respond to STAg stimulation. Supernatants from the cell cultures were used to determine IL-2, IL-12, IFN- $\gamma$, and IL-4 production. The unresponsiveness of spleen cells in AhR-/- mice was in accordance with low levels of IL-2 observed in the supernatants (Figure 4(b), $P<.05$ ). Interestingly, higher levels of IFN$\gamma$ were detected in supernatants of STAg-stimulated spleen cells from AhR-/- compared to WT mice (Figure 4(d)). In contrast, no differences in IL-12 (Figure 4(c)) and IL-4 levels (data not shown) were observed in the same cultures.

3.4. Overproduction of IL-12 and IFN- $\gamma$ in Peritoneal Exudate Cells from AhR-/- Mice. It is well known that mononuclear phagocytes are important in controlling the early stage of $T$. gondii infection by early and continuous production of IL-12, which is a key lymphokine that mediates host resistance to T. gondii infection $[45,46]$. Therefore, we asked whether IL12 production by mononuclear cells was altered in T. gondiiinfected AhR-/- mice. To assess this, we compared the ability of AhR-/- and WT peritoneal exudate cells (PECs) to produce IL-12 and IFN- $\gamma$ in response to STAg or medium alone for 48 hours. As seen in Figure 5, PECs from mice lacking AhR produced greater amounts of IL-12 and IFN- $\gamma$ than WT mice (Figures 5(a)-5(b), resp.).

3.5. AhR-/- Mice Exhibit Greater Liver Damage than WT Mice. From the above observations, we hypothesized that the immunopathology and death observed in infected AhR-/- mice were due to overexpression of proinflammatory 

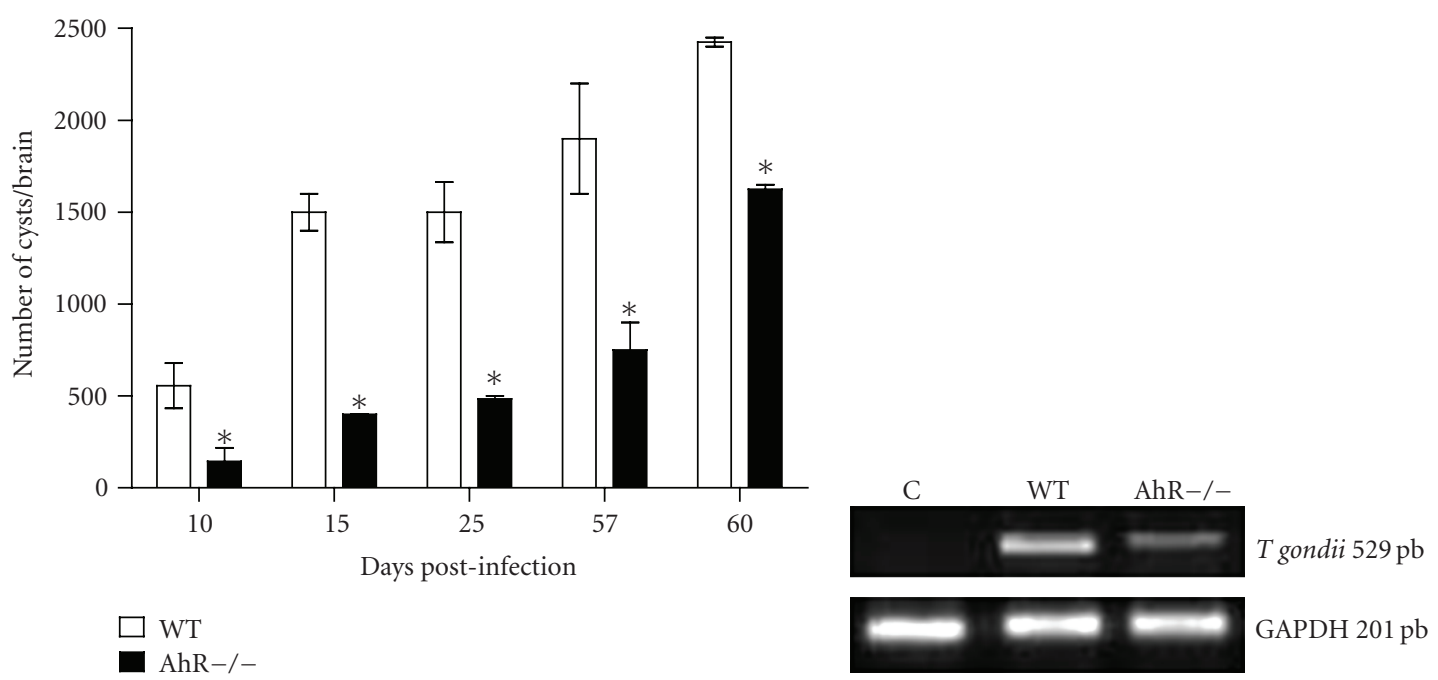

(a)

(b)

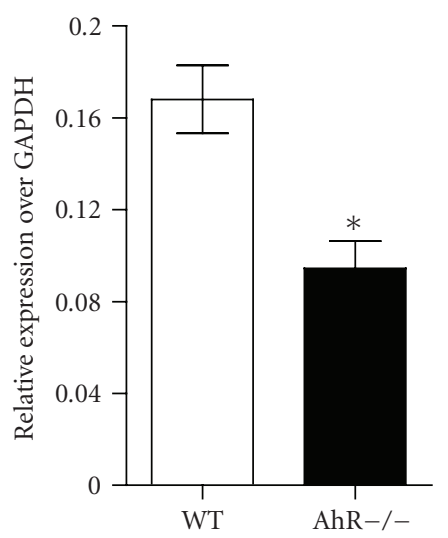

(c)

Figure 2: Parasite burden in T. gondii-infected AhR-/- and WT mice after i.p. injection with ME49 strain of T. gondii. (a) Number of cysts per brain obtained after a kinetics of days p.i. as counted under the microscope (40X magnification). Data are representatives of three independent experiments where $n=$ five mice per group $\left({ }^{*} P<.01\right.$ with respect to WT, student's $t$-test). (b) T. gondii gene expression by semiquantitative PCR was performed in brains of noninfected mice (letter C) and WT and AhR-/- mice at 25 days post T. gondii infection using primers specific for the sequence of the T. gondii gene: A representative gel electrophoresis from three independent experiments. (c) PCR analysis for detection of T. gondii in brains of WT and AhR-/- mice at 25 days post T gondii infection (Student's $t$-test).

cytokines. To confirm this hypothesis, portions of the livers from infected WT and AhR-/- mice were subjected to histopathology. At day 10 post infection livers of infected WT mice presented a small number of mononuclear inflammatory foci; however, more number of small granulomas and inflammatory infiltrates were observed in livers from AhR-/- mice at 10 days post infection (Figure 6(a)). At day 25 post infection, inflammatory infiltrate was present, but granulomas were rarely observed, and when present, were smaller in livers from infected WT mice (Figure 6(b)). In contrast, livers from T. gondii-infected AhR-/- mice exhibited a large area of granulomas and had more mononuclear inflammatory infiltrates scattered by parenchyma and portal areas than T. gondii-infected WT mice. Additionally, detection of alanine aminotransferase (ALT) and aspartate aminotransferase (AST) confirmed the extent of damages induced by the inflammatory response in livers, as liver samples from infected AhR-/- mice produced higher levels of AST and ALT at 25 days after infection, when inflammatory infiltrates and granulomas were detected in livers of T. gondiiinfected AhR-/- mice (Figures 6(c) and 6(d), resp.).

3.6. Quantification of IFN- $\gamma, I L-10$, and GATA-3 in Spleen Cells and Brains by RT-PCR. Given that GATA-3 is a key factor for Th2 differentiation, we investigated whether AhR deficiency had an effect on GATA-3 mRNA expression in spleen cells and brains from T. gondii-infected AhR-/- and WT mice at 25 days post infection. Comparable levels of IFN- $\gamma$ mRNA were detected in spleen cells and brains from AhR-/- and WT mice. However, spleen cells and brains of AhR-/- mice expressed lower transcript levels of both GATA3 and IL-10 compared to WT mice (Figures 7(a) and 7(b), resp.). 


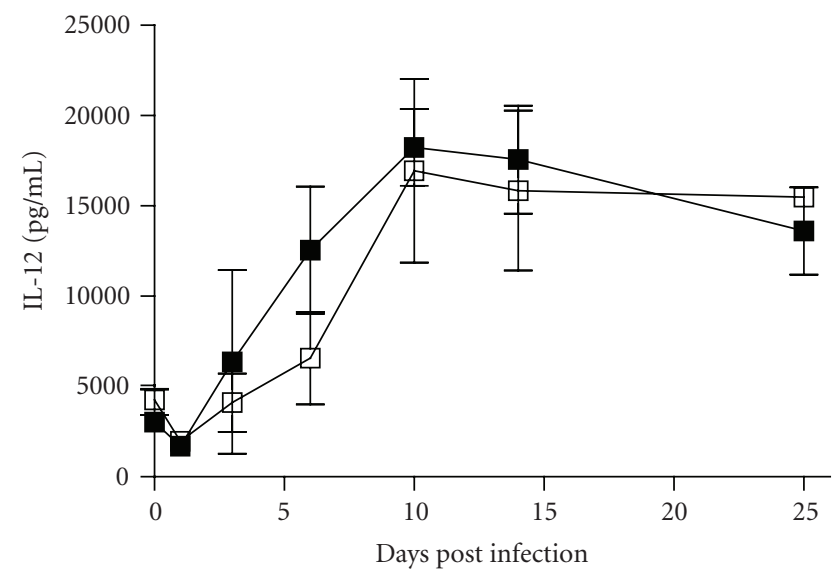

(a)

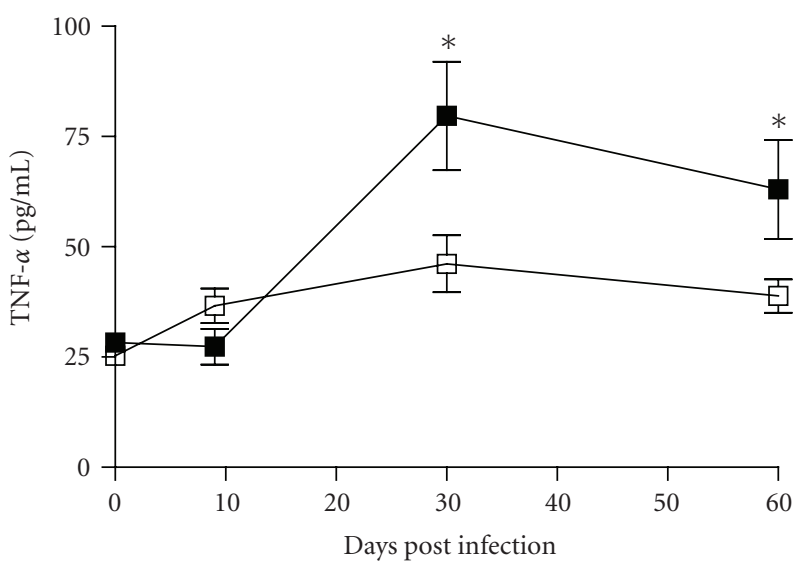

$\square$ WT

-1 AhR-/-

(c)

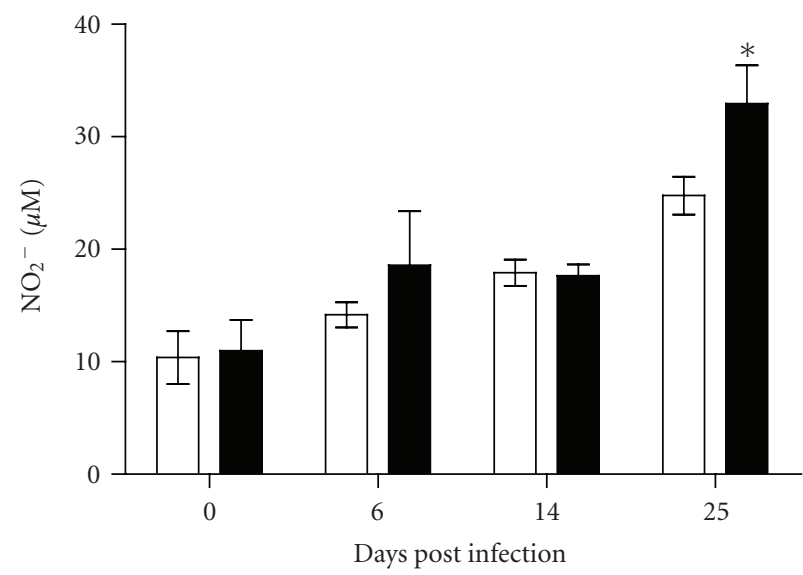

$$
\square \mathrm{WT}
$$

- AhR-/-

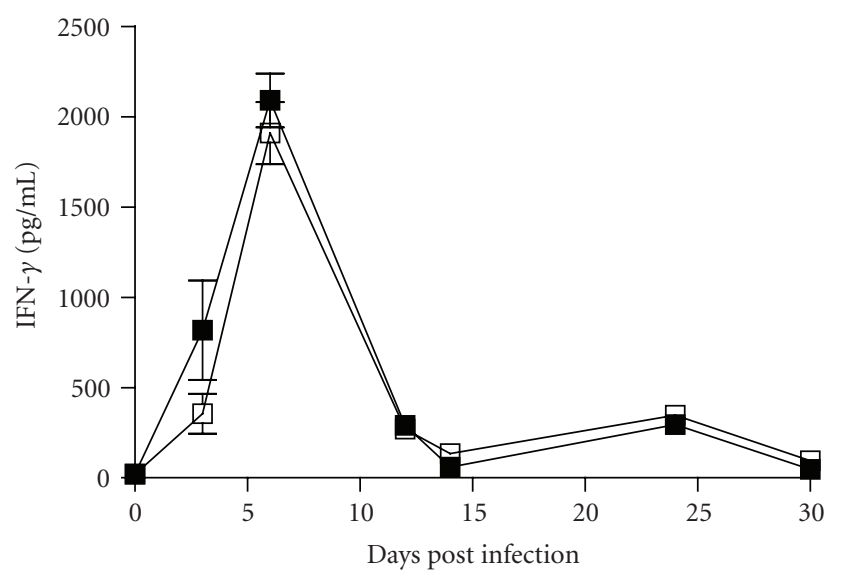

(b)

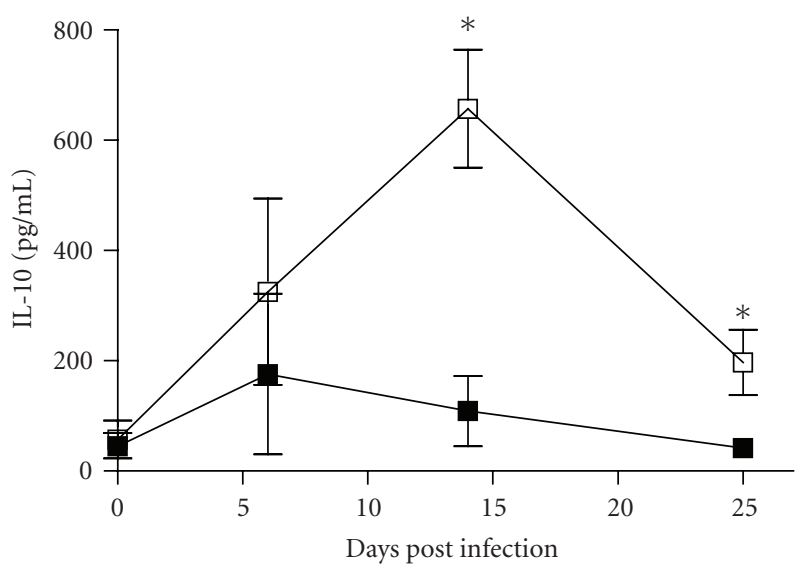

$\square$ WT

$\rightarrow$ AhR-1-

(d)

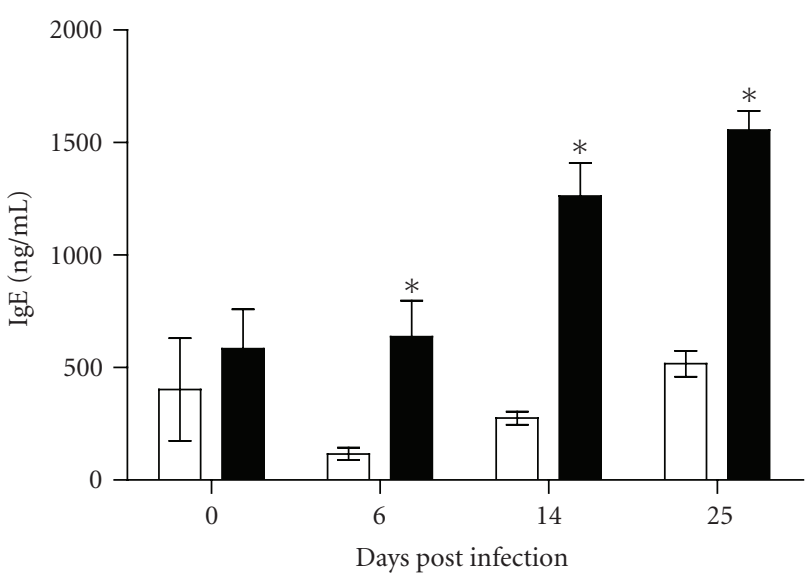

$\square$ WT

- $\mathrm{AhR}-/-$

(e)

FIgURE 3: Levels of IL-12p70 (a), IFN- $\gamma$ (b), TNF- $\alpha$ (c), IL-10 (d) nitric oxide (e), and total IgE (f) in sera from AhR-/- and WT mice infected with 40 cysts of $T$. gondii. For systemic cytokine, nitric oxide, and IgE production, mice were bled at the indicated time points and the levels of cytokines and total IgE (f) were measured in serum by ELISA and nitric oxide (e) was measured in serum by Griess assay as described above. The values presented are the mean $\pm \mathrm{SD}$ of triplicate samples of 6 animals per time point per group. ${ }^{*} P<.05$ with respect to WT, Student's $t$-test. 

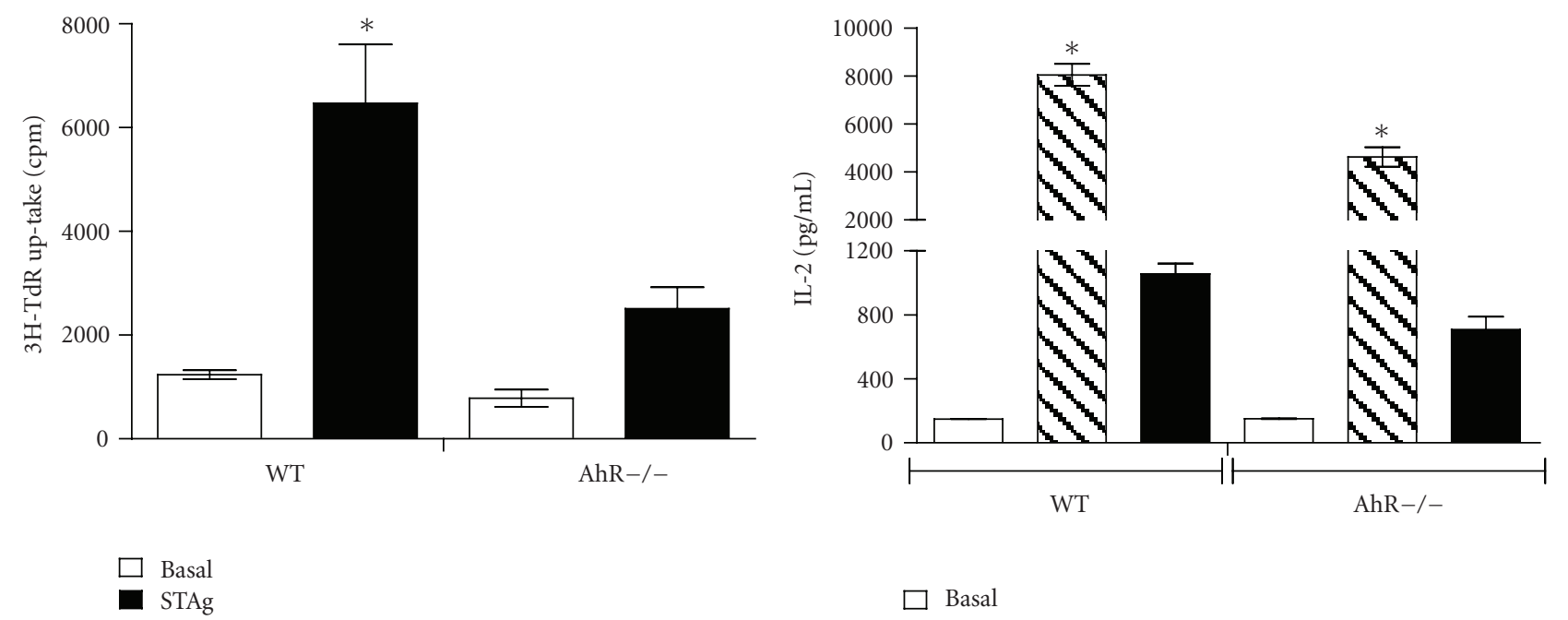

$$
\begin{aligned}
& \square \text { Basal } \\
& \text { v ConA } \\
& \square \text { STAg }
\end{aligned}
$$

(a)
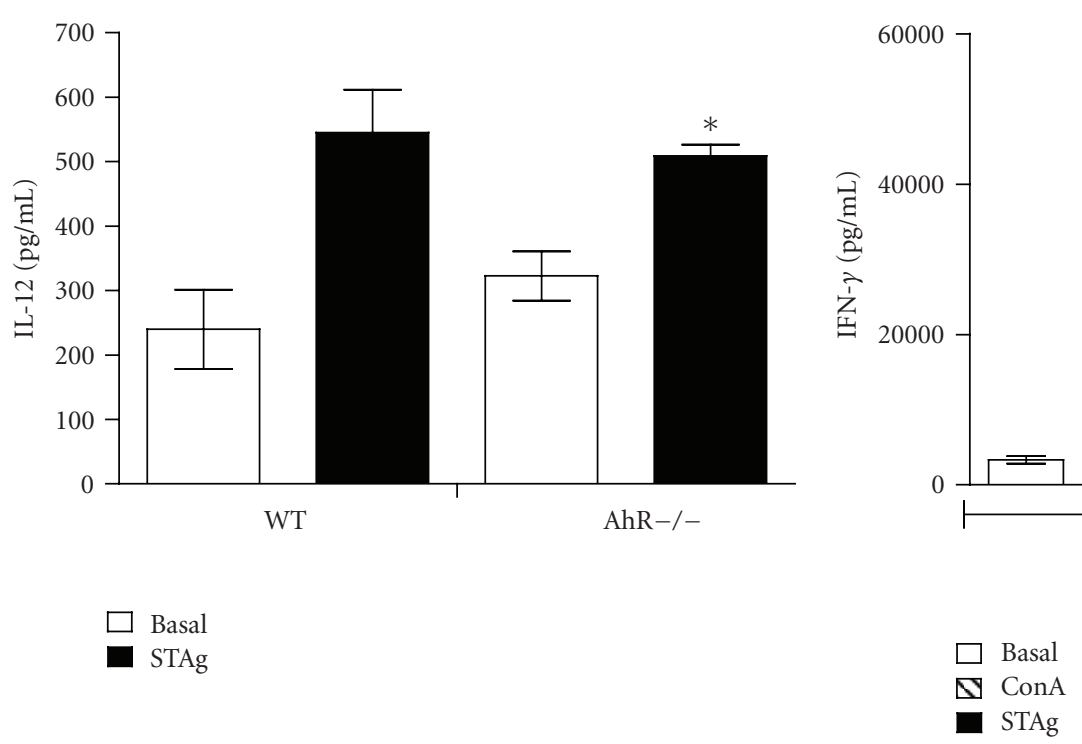

(c)

(d)

FIGURE 4: STAg-induced proliferative responses of spleen cells. Isolated spleen cells from T. gondii-infected (25 days p.i.) WT or AhR-/- mice were stimulated with $2.5 \mu \mathrm{g} / \mathrm{mL}$ of STAg for 5 days in vitro. ${ }^{3}[\mathrm{H}] \mathrm{TdrU}$ was added $(0.5 \mu \mathrm{Ci} /$ well $) 20$ hours before harvesting, and counts per minute (cpm) were calculated using a liquid scintillation counter (a). Secretion of IL-2 (b), IL-12 (c), and IFN- $\gamma$ (d) in supernatants recovered from cell cultures were evaluated by an ELISA-sandwich. Means \pm SE, $n=5 .{ }^{*} P<.05$, Student's $t$-test.

3.7. FACS Analysis. Upon establishing that deaths of AhR-/mice infected with $T$. gondii is likely due to a high proinflammatory response that may control parasite replication but, at the same time, cause severe systemic damage to the host, we asked whether AhR deficiency had a role on the immunophenotyping of $\mathrm{T}$ cell subpopulations. To test this, spleen cells were obtained at 25 days post infection and incubated with $2.5 \mu \mathrm{g} / \mathrm{mL}$ of STAg ex vivo for 5 days, and CD4+, CD8+, and CD4+/CD25+/Foxp3+ (T regulatory lymphocytes- $\mathrm{T}_{\text {reg }}$ ) lymphocyte subpopulations were quantified. As shown in Table 2, the proportion of STAg-specific CD4+ or CD8+ T cells (Table 2) were comparable between AhR-/- and WT mice. Interestingly, a slight, but not significant, decrease in STAg-specific $\mathrm{T}_{\text {reg }}$ cells was observed in AhR-/- mice compared to WT mice (Table 2). Taken as a whole, these data show that AhR-/- mice are capable of developing an adaptive immune response.

Macrophages are very important innate immune cells that respond promptly to T. gondii infection as well as to its soluble antigen. Moreover, it is well known that CCR5 is one of the main receptors for STAg that is involved in triggering the early production of IL-12 and TNF- $\alpha$ [47]. Hence, to determine whether AhR deficiency phenotypically and functionally alters these cell populations, we analyzed the 


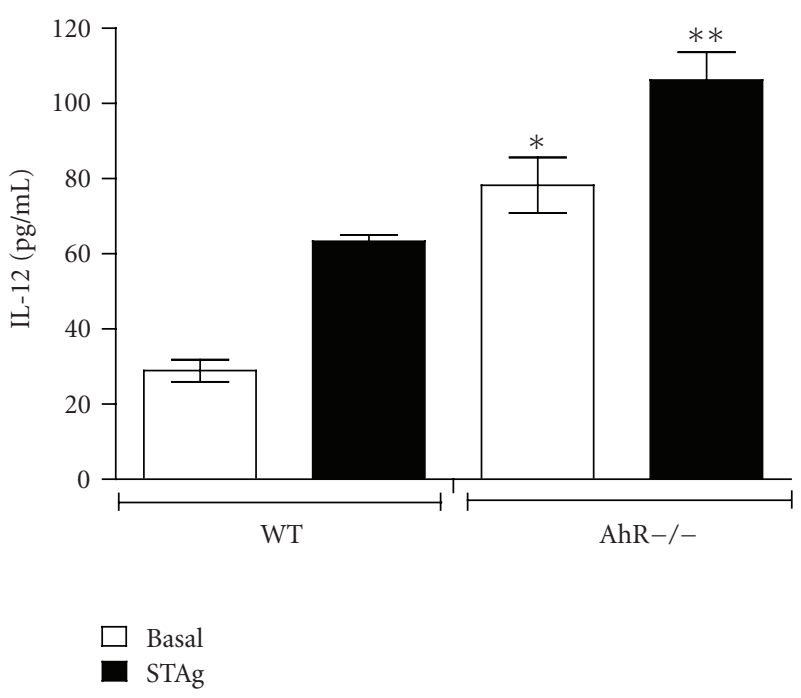

(a)

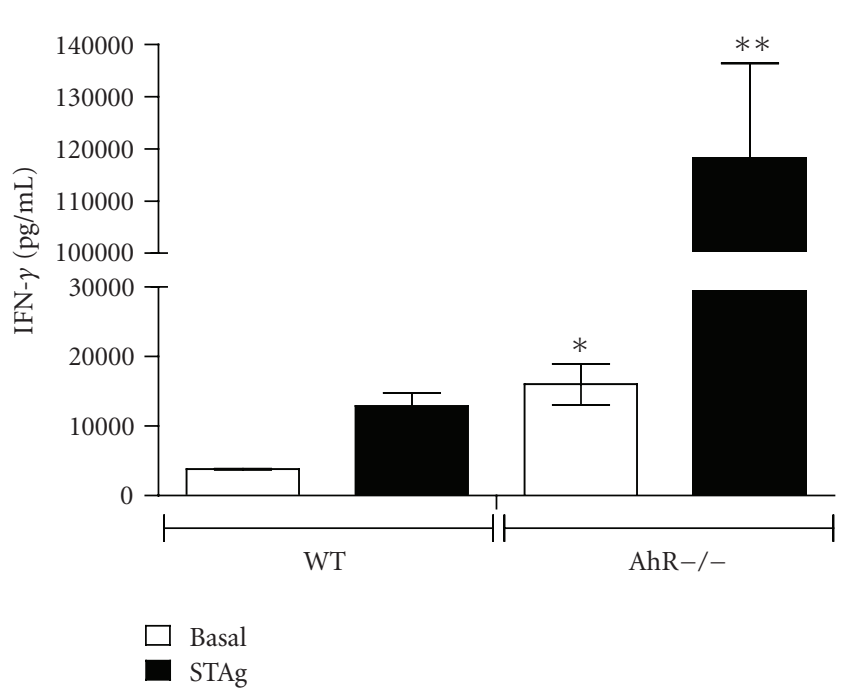

(b)

FIgure 5: IL-12 and IFN- $\gamma$ levels of PECs from T. gondii-infected AhR-/- and WT mice. After 25 days of T. gondii infection, PECs from AhR/- or WT mice were recovered and restimulated in vitro with $2.5 \mu \mathrm{g} / \mathrm{mL}$ of STAg for 24 hours. The IL-12 and IFN- $\gamma$ levels were determined by ELISA-sandwich on supernatants recovered from cultures. Means \pm SE, $n=5 .{ }^{*} P<.05$ with respect to basal bars values. ${ }^{* *} P<.05$ with respect to STAg stimulus, Student's $t$-test.

TABLE 2: Flow cytometric profiles of spleen cells stained for CD4+, CD8+, and CD4+/CD25+/Foxp3+ (Treg). Data are shown as \% of T. gondii-specific CD4+, CD8+, and Treg cells from 4 to 5 mice per group.

\begin{tabular}{lcc}
\hline & WT $(\%)$ & AhR-/- $(\%)$ \\
\hline CD4+ & $26.0 \pm 2.3$ & $25.4 \pm 2.7$ \\
CD8+ & $12.7 \pm 1.5$ & $13.2 \pm 0.9$ \\
CD4+/CD25+/Foxp3+ & $9.5 \pm 2.37$ & $7.4 \pm 2.8$ \\
\hline
\end{tabular}

expression of CCR5 and TLR2, another molecule that may be involved in T. gondii recognition, on peritoneal adherent macrophages isolated from AhR-/- and WT mice 25 days after infection. AhR-/- mice displayed at least 50\% lower expression of TLR2 mainly on F4/80+ cells (Figure 8(a)). In contrast, expression of CCR5 was unaltered in the same population (Figure 8(b)).

3.8. AhR-/- Mice Exhibit Decreased 5-LOX mRNA Expression. It has been demonstrated that the eicosanoid called lipoxin $\mathrm{A}_{4}$ $\left(\mathrm{LXA}_{4}\right)$ plays a role in the anti-inflammatory response against T. gondii [33]. Interestingly, $\mathrm{LXA}_{4}$ is an endogenous ligand for $\mathrm{AhR}$, and the binding of $\mathrm{AhR}$ with $\mathrm{LXA}_{4}$ controls the expression of proinflammatory cytokines such as IL12 and IFN- $\gamma$ [48]. Given that the expression of $\mathrm{LXA}_{4}$ is dependent on the expression of 5-lipoxygenase (5-LOX) $[33,48]$, we asked whether expression of 5-LOX may be affected in T. gondii-infected AhR-/- mice. As seen in Figure $8(\mathrm{c})$, the transcript levels of 5-LOX in spleen cells were significantly lower in AhR-/- mice compared to WT-infected mice (Figure 8(c)).

\section{Discussion}

AhR has been suggested to play an important role in the immune response to virus and bacterial infections, where a functional innate immune response is pivotal for complete resistance to the pathogens $[20,22,49]$. However, in those studies the molecular mechanism associated with AhR was not too clear. Thus, establishment of the role of AhR in response to parasitic infections may help in understanding the endogenous immune function of AhR.

Here, we showed that AhR deficient mice (AhR-/-) are more susceptible to T. gondii infection than WT mice. After peritoneal infection with 40 cysts AhR-/- mice succumbed to $T$. gondii infection faster than WT mice; however, AhR/- mice developed fewer brain cysts, despite higher serum levels of TNF- $\alpha$, nitric oxide (NO) and IgE and lower serum levels of IL-10 compared to infected WT mice. The high mortality rates in AhR-/- mice suggest that AhR is critical in the host defense against toxoplasmosis; however, the lower number of cysts in the brain in conjunction with high levels of TNF- $\alpha$, and NO in AhR-/- mice suggests that the higher mortality rate is not caused by the inability to restrict parasite replication.

Resistance to experimental toxoplasmosis has been shown to be dependent on production of several proinflammatory cytokines (MIF, IL- $1 \beta$, IL-12, TNF- $\alpha$, and IFN$\gamma)$ and NO $[25,29,30,50]$. Furthermore, the powerful proinflammatory immune response together with IgE, an antibody that has been correlated with early acute inflammation in toxoplasmosis [51, 52], and NO [53] restricts dissemination of the parasite and prevents death by parasitic infection. After parasite dissemination has been contained by IFN- $\gamma$-dependent responses, the onset of the 

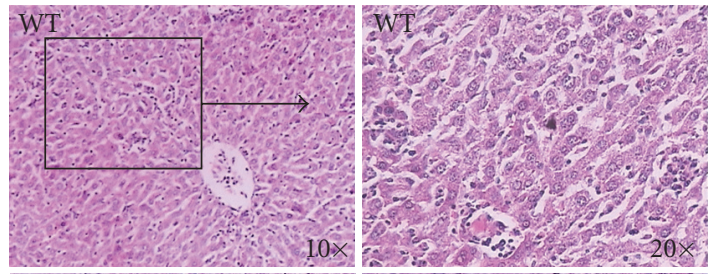

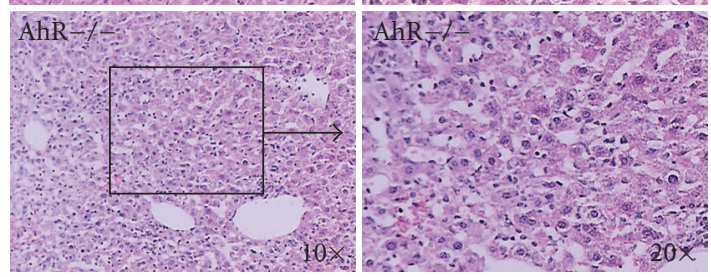

(a)

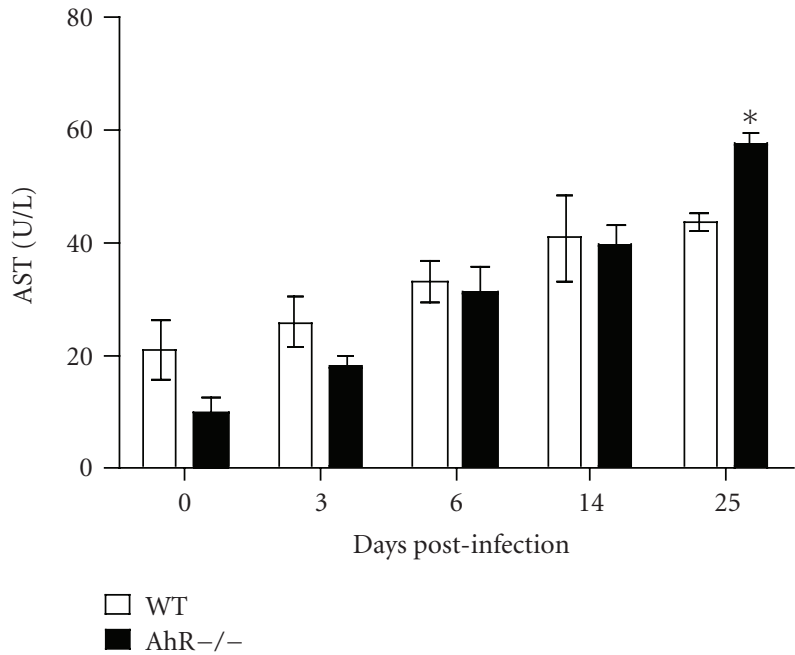

(c)
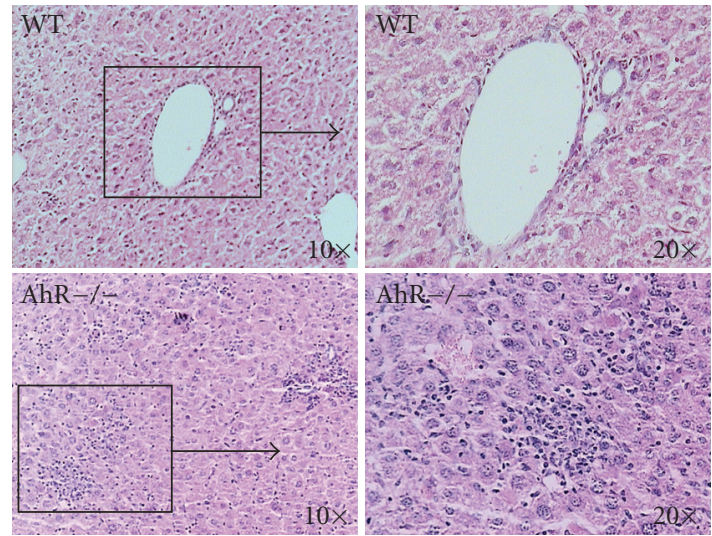

(b)

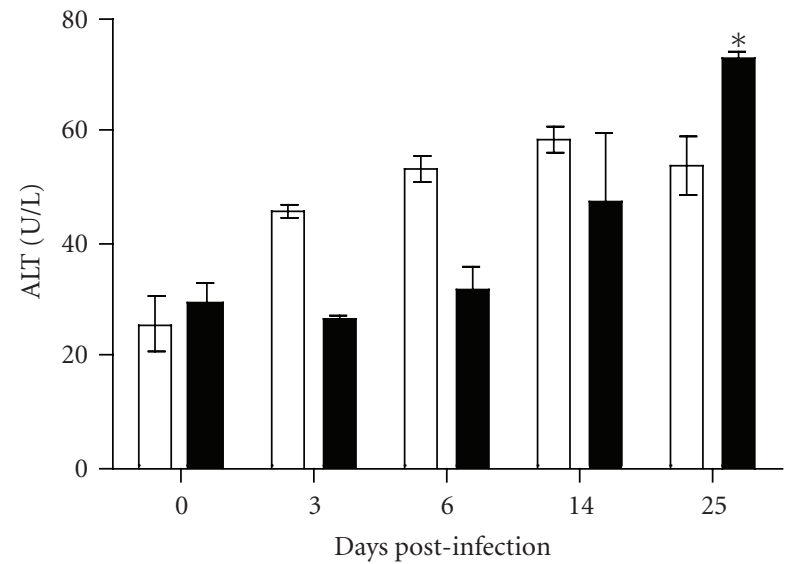

$\square$ WT

Figure 6: Representative histopathological liver changes after 10 days (a) or 25 days (b) of infection with 40 cysts of T. gondii. Note the mass of necrosis observed by $\mathrm{H} \&$ E staining (arrow). (c) Serum transaminase levels on AhR-/- and WT infected mice. ${ }^{*} P<.05$, Student's $t$-test.

chronic phase of infection is characterized by continuous cell-mediated immunity. Such potent responses are kept under tight control by anti-inflammatory cytokines such as IL-10, which is required for preventing necrosis in the small intestine and death in both genetically resistant $\mathrm{BALB} / \mathrm{c}$ and susceptible $\mathrm{C} 57 \mathrm{BL} / 6$ mice following infection with $T$. gondii [54]. Thus, these first results suggest that high production of inflammatory cytokines in conjunction with low levels of IL-10 could reduce dissemination of brain cysts without preventing mortality, possibly because the inflammatory response causes systemic damage.

To test the above hypothesis, we analyzed the $\mathrm{T}$ cell response by comparing the proliferative capacity and cytokine production in spleen cells from AhR-/- and WT infected mice in the presence of STAg. The proliferation and IL-2 production in AhR-/- infected mice were diminished. These observations were in line with previous report that show that embryonic fibroblasts from AhR-/- mice exhibit a lower proliferation rate and impaired IL-2 production
[55] associated with the fact that the IL-2 promoter region contains distal regulatory elements that can be addressed by the AhR to induce IL-2 and cooperate with the proximal promoter in this [8]. Moreover, it is well known that TNF- $\alpha$ and IFN- $\gamma$ have antiproliferative properties [52]. We detected high levels of TNF- $\alpha$ in serum, which could have contributed to low levels of proliferation in T. gondii-infected AhR-/mice.

In accordance with our initial hypothesis, we found high levels of IFN- $\gamma$ in the supernatant of spleen cells from infected AhR-/- mice. Somewhat to our surprise, no difference in IL-12 levels was detected in supernatants of spleen cell cultures between AhR-/- and WT mice. However, this inconsistency was not observed in supernatants from restimulated STAg PECs. The levels of IL-12 and IFN- $\gamma$ in supernatants of AhR-/- PECs were significantly higher than those in WT-PECs. These observations were consistent with the extensive histopathological damage in livers and high levels of ALT and AST detected in sera. Together, the high production of inflammatory cytokines in conjunction with 


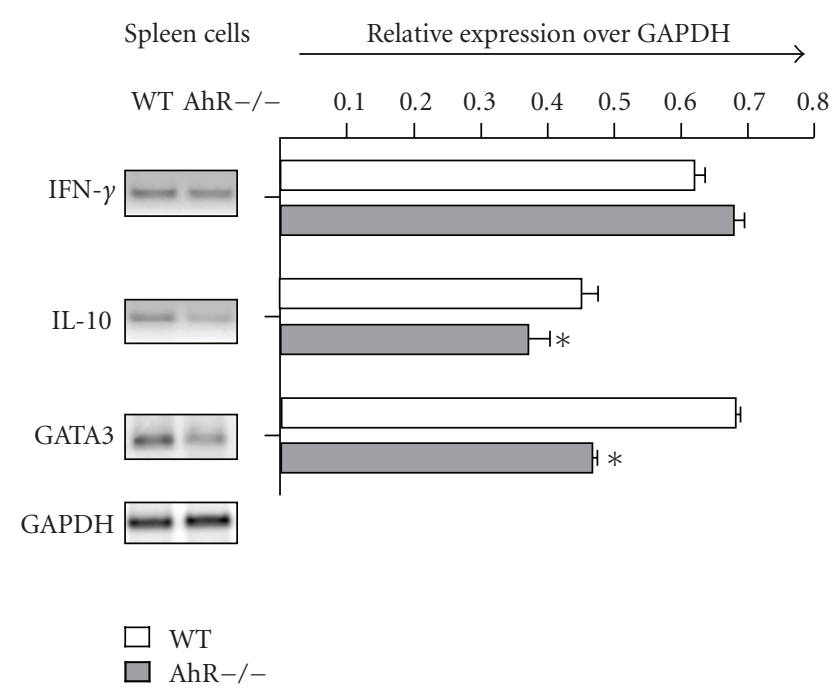

(a)

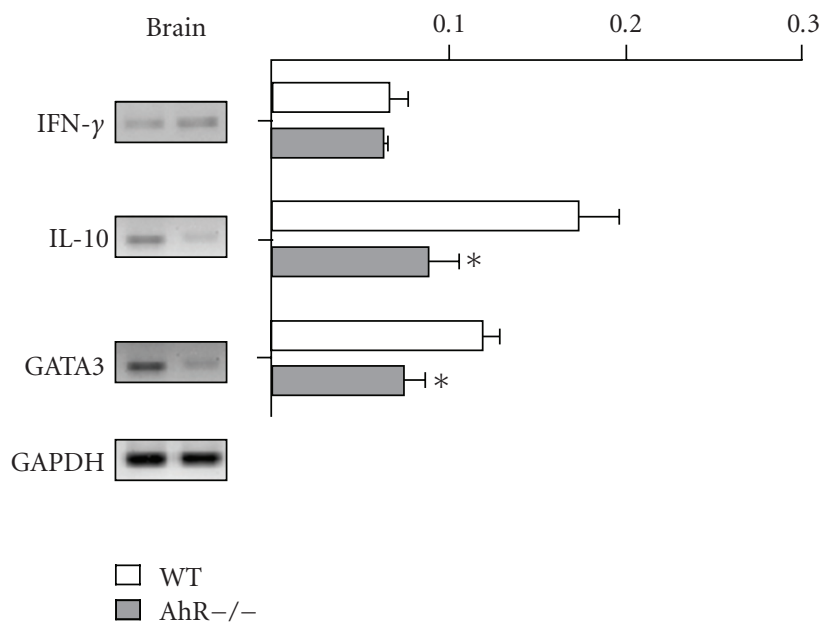

(b)

Figure 7: Gel electrophoresis on IFN- $\gamma$, IL-10, GATA-3, and GAPDH-amplified products. Total RNA was isolated from Splenocytes (a) or brain tissue (b) from WT and AhR-/- mice at 25 days after T gondii infection as described in Materials and Methods. The resulting fragments migrated along with the 200-500 bp fragment of the $100 \mathrm{~kb}$ marker used. The exact fragment sizes are listed in Table 1.

low levels of IL-10 may mediate the damage in AhR-/- mice and may contribute to the high mortality rate observed in $T$. gondii-infected AhR-/- mice.

Previous studies have suggested that AhR has a role in modulating the balance between Th1 and Th2 response $[10,15]$. Therefore, we asked whether high levels of proinflammatory cytokines favor Th1 polarization in AhR-/- mice. The mRNA expressions of IFN- $\gamma$, IL-10, and GATA- 3 were determined by RT-PCR in spleen cells and brains from infected AhR-/- and WT mice. Contrary to what we expected, we did not observe any significant difference in IFN- $\gamma$ mRNA levels in either spleen cells or the brains between AhR/- and WT mice. In contrast, reduced levels of IL-10 and GATA-3 were observed in AhR-/- mice compared to WT mice. We suggest that the reduction of GATA-3 and IL-10 observed in T. gondii-infected AhR-/- mice is responsible for potentiating the biological activity of IFN- $\gamma$, rather than favoring polarization of the immune response toward a Th1 response.

Recent results suggest that AhR can regulate the generation of regulatory $\mathrm{T}$ cells $\left(\mathrm{T}_{\text {regs }}\right)$, a main source of IL-10, since AhR activation by TCDD induces differentiation of Tcell progenitor cells into $\mathrm{T}_{\text {regs }}$ [56]. Given that infected AhR/- mice display low levels of IL-10, one possibility is that $T_{\text {regs }}$ subpopulation is reduced in the absence of AhR. However, this idea was disproved by our observation that no significant differences were observed in the proportion of $\mathrm{T}_{\text {regs }}$ cell subpopulations between AhR-/- and WT mice. Furthermore, no significant differences were noted in CD4+ and CD8+ T cell subpopulations between T. gondii-infected AhR-/- and WT mice. These results suggest that AhR is not required for adaptive $\mathrm{T}$ cell response during toxoplasmosis, at least in those subpopulations analyzed. The production of cytokine IL-12 is critical for the development of IFN- $\gamma$ dependent resistance to T. gondii infection (Aliberti J Alan Sher JEM 196 No.9 2002).The signaling pathway through CC chemokine receptor 5 (CCR5) plays a critical role in triggering IL-12 production, mainly by CD $8 \alpha+$ subset of dendritic cells (DC) upon stimulation with STAg $[33,47]$. Since macrophages also display CCR5 expression, we considered the possibility that overexpression of CCR5 on macrophages might be responsible for the high levels of IL-12 secreted by PECs from T. gondii-infected AhR-/- mice. However, in the present study, there was no significant difference in CCR5 expression on $\mathrm{F} 4 / 80+$ cells between infected AhR-/- and WT mice. This observation shows that, at least in macrophages, CCR5 expression is not affected by the lack of AhR.

Toll-like receptors (TLRs), which are innate immune receptors, are also involved in the recognition of $T$. gondii profilin. TLR11 is the main receptor that plays a major role in IL-12-dependent control of T. gondii, although other TLR family members also contribute to host resistance to this protozoan pathogen [57]. Thus, while TLR2 deficient mice display a normal IL-12 production and resist $T$. gondii infection at conventional doses, they are susceptible when challenged with higher infective doses, arguing for a cooperative role of TLR2 in controlling the parasite [58]. Moreover, recently it has been described that both human and murine bone marrow-derived DC expressing high levels of TLR2 favor an anti-inflammatory response characterized by enhanced IL-10 production [59-61]. Therefore TLR2 triggering mediates IL-10 upregulation. Here we showed that macrophages from T. gondii-infected AhR-/- mice expressed significantly less TLR2 as compared to WT mice. This observation supports the notion that lower expression of TLR2 on macrophages contributes to reduce IL-10, favoring the robust proinflammatory response observed in T. gondiiinfected AhR-/- mice. 

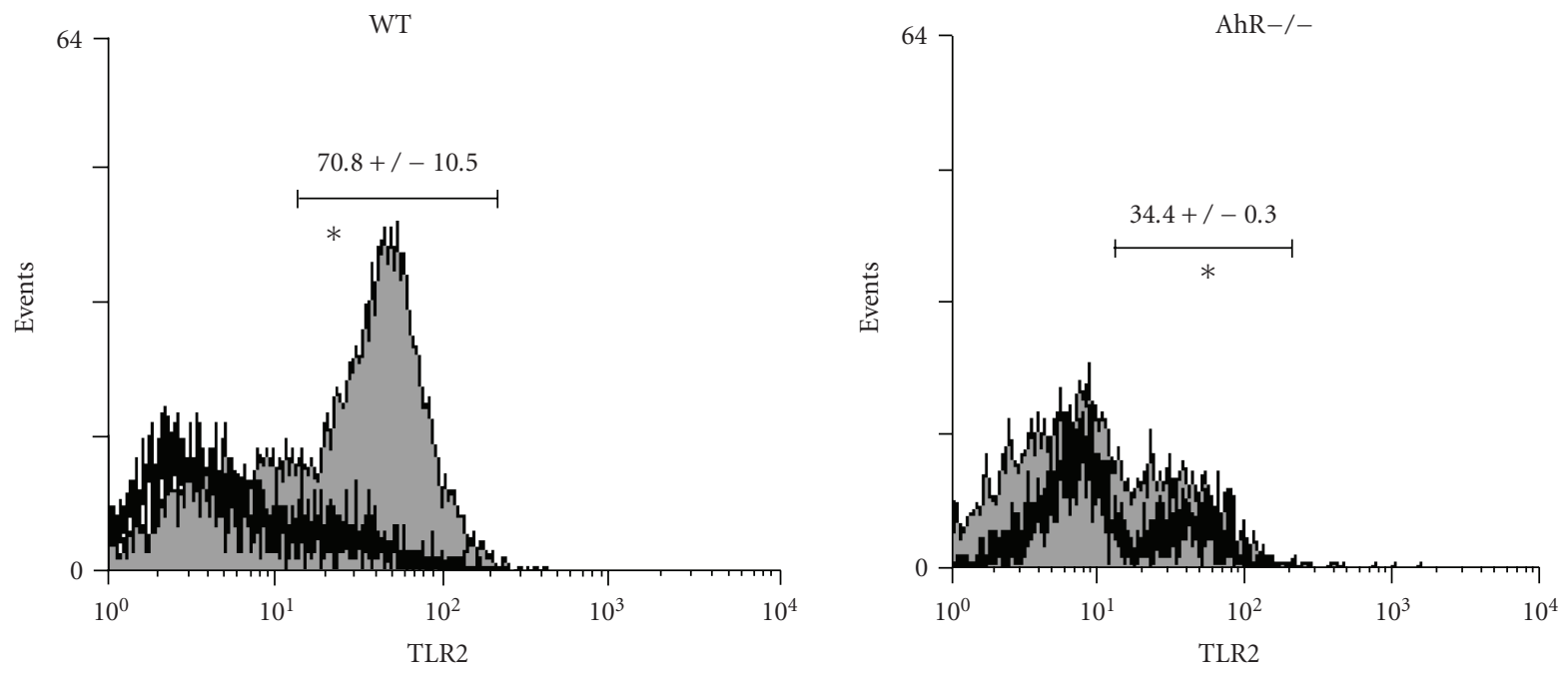

(a)
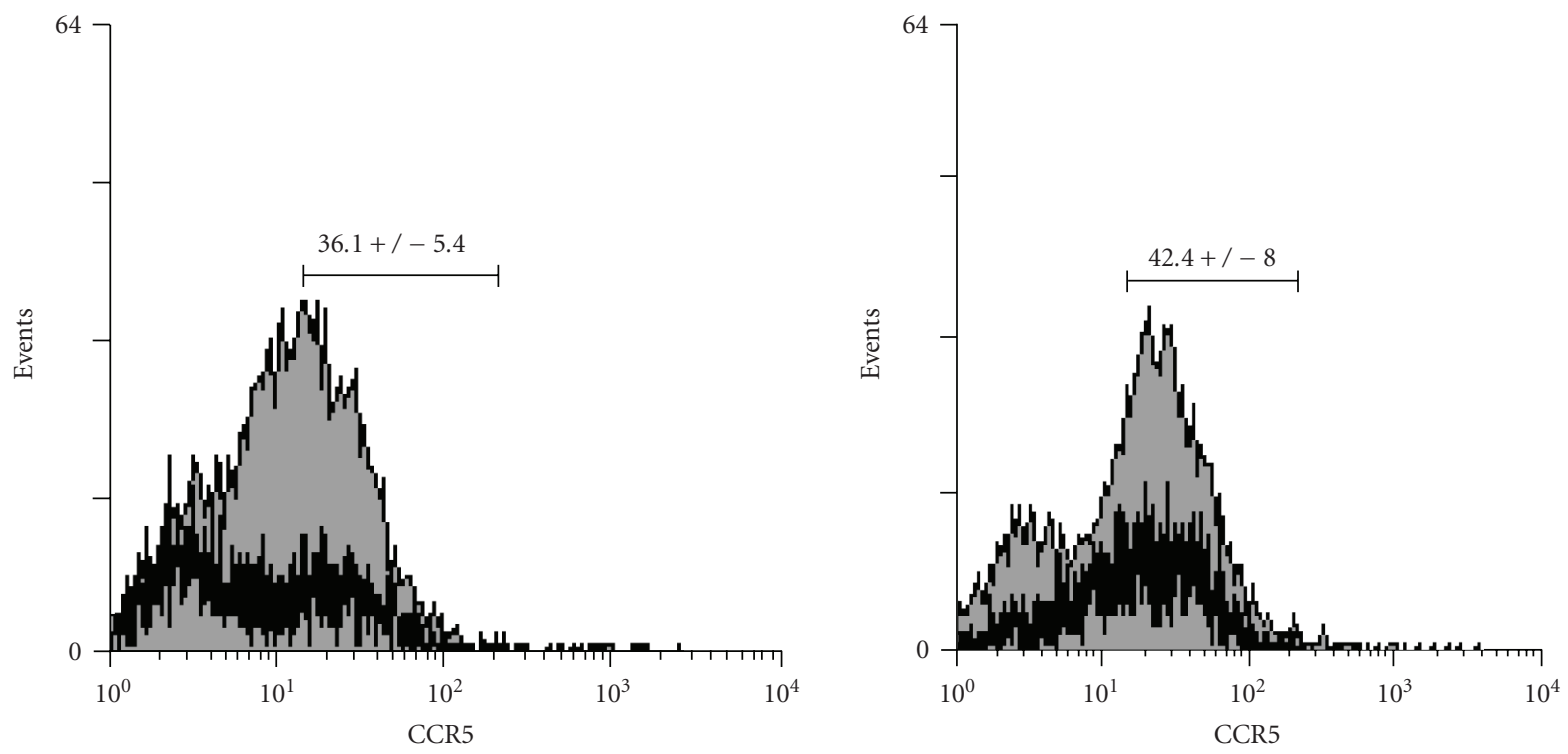

(b)

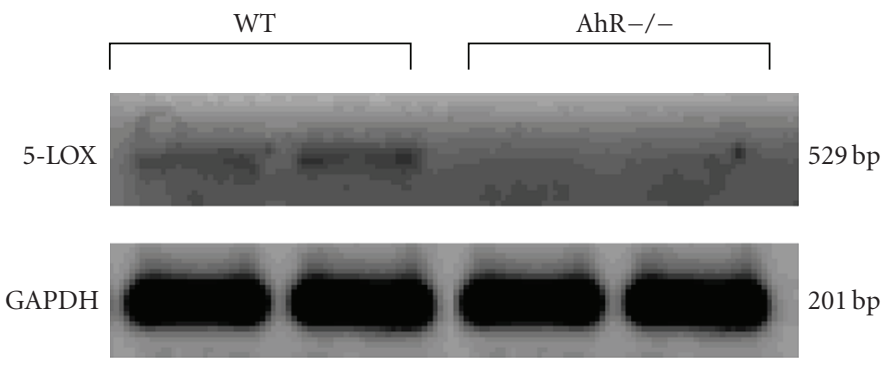

(c)

FIGURE 8: Flow cytometric profiles of adherent exudate macrophages stained for TLR2 and CCR5. The histograms represent TLR2 (a) or CCR5 (b) versus F4/80 expression on adherent macrophages from AhR-/- or WT mice challenged with STAg for 24 hours after 25 days of T. gondii infection: Nonstimulus (dark line) and STAg stimulus (gray curve). Shown are representative data from three to four independent experiments. Significances were calculated by Student's t test. ${ }^{*} P<.05$ WT versus AhR-/-. Gel electrophoresis of 5-LOX and GAPDHamplified products (c). Total RNA was isolated from splenocytes from WT and AhR-/- mice at 25 days after T. gondii infection as described in Materials and Methods. 
Modulation of CCR5 on DCs involves ligation of G protein-coupled receptor formyl peptide receptor-like 1 (FPRL-1). $\mathrm{LXA}_{4}$, an arachidonate-derived inhibitor of acute inflammation, has been suggested to bind to two receptors: FPRL-1 (therefore could induce CCR5 downmodulation) and AhR [62].

In vivo injection of STAg triggers production of endogenous $\mathrm{LXA}_{4}$ in a 5-lipoxygenase-(5-LOX-) dependent manner causing suppression of IL-12 production by DCs [33]. Furthermore, upon infection with $T$. gondii, serum levels of $\mathrm{LXA}_{4}$ increase steadily in WT mice over the course of the acute phase and remain high during the chronic phase [33]. Moreover, induction of SOCS-2, an intracellular mediator of anti-inflammatory response, upon STAg injection requires 5-LOX and AhR [48]. Interestingly, 5-LOX-deficient mice succumb to $T$. gondii infection at the early onset of chronic disease with excessive production of proinflammatory cytokines and substantially fewer brain cysts, suggesting that the excessive proinflammatory response in brains of 5LOX-deficient hosts is responsible for the mortality [63]. In line with this, we found that 5-LOX expression in spleen cells was significantly decreased in T. gondii-infected AhR-/- mice. Thus, one possible mechanism by which the absence of AhR may cause these enhanced inflammatory responses can be the lack of interaction between $\mathrm{AhR}$ and $\mathrm{LXA}_{4}$, through the absence of expression of 5-LOX, which leads to a failure to control the magnitude of the inflammatory response induced by $T$. gondii infection. Further research will be necessary to prove this hypothesis.

In summary, we presented here experimental evidence for a regulatory role of AhR during experimental toxoplasmosis using AhR-/- mice. Our data suggest that AhR is not required for adaptive $\mathrm{T}$ cell response to $T$. gondii infection but may play a constitutive role in the innate immune response to toxoplasmosis by dampening the inflammatory responses. These studies represent the first demonstration that AhR is critically involved during a protozoan infection.

\section{Acknowledgments}

The authors thank Cesar Terrazas for helpful discussion. They also thank Dr. Leticia Moreno-Fierros for the PEanti-CD25 antibody, Dr. Leticia Verdín, Dr. Elsa Calleja, and Biologist Ana Federica for their technical assistance on histopathology. This work was supported in part by Grants from the National Council of Science and Technology of Mexico (CONACyT) 49812-Q, 36272-M, and PAPIITUNAM Grant IN213009-3.

\section{References}

[1] J. P. Whitlock Jr., "Induction of cytochrome P4501A1," Annual Review of Pharmacology and Toxicology, vol. 39, pp. 103-125, 1999.

[2] M. S. Denison and S. R. Nagy, "Activation of the aryl hydrocarbon receptor by structurally diverse exogenous and endogenous chemicals," Annual Review of Pharmacology and Toxicology, vol. 43, pp. 309-334, 2003.
[3] Z.-W. Lai, C. Hundeiker, E. Gleichmann, and C. Esser, "Cytokine gene expression during ontogeny in murine thymus on activation of the aryl hydrocarbon receptor by 2,3,7,8tetrachlorodibenzo-p-dioxin," Molecular Pharmacology, vol. 52, no. 1, pp. 30-37, 1997.

[4] B. A. Jensen, R. J. Leeman, J. J. Schlezinger, and D. H. Sherr, "Aryl hydrocarbon receptor (AhR) agonists suppress interleukin-6 expression by bone marrow stromal cells: an immunotoxicology study," Environmental Health, vol. 2, article 1, pp. 1-13, 2003.

[5] M. N’Diaye, E. Le Ferrec, D. Lagadic-Gossmann, et al., "Aryl hydrocarbon receptor- and calcium-dependent induction of the chemokine CCL1 by the environmental contaminant benzo[a]pyrene," Journal of Biological Chemistry, vol. 281, no. 29, pp. 19906-19915, 2006.

[6] C. F. A. Vogel, E. Sciullo, P. Wong, P. Kuzmicky, N. Kado, and F. Matsumura, "Induction of proinflammatory cytokines and C-reative protein in human macrophage cell line U937 exposed to air pollution particulates," Environmental Health Perspectives, vol. 113, no. 11, pp. 1536-1541, 2005.

[7] T. K. Warren, K. A. Mitchell, and B. P. Lawrence, "Exposure to 2,3,7,8-tetrachlorodibenzo- $p$-dioxin (TCDD) suppresses the humoral and cell-mediated immune responses to influenza A virus without affecting cytolytic activity in the lung," Toxicological Sciences, vol. 56, no. 1, pp. 114-123, 2000.

[8] M.-S. Jeon and C. Esser, "The murine IL-2 promoter contains distal regulatory elements responsive to the Ah receptor, a member of the evolutionarily conserved bHLH-PAS transcription factor family," Journal of Immunology, vol. 165, no. 12, pp. 6975-6983, 2000.

[9] J.-H. Yang, C. Vogel, and J. Abel, "A malignant transformation of human cells by 2,3,7,8-tetrachlorodibenzo- $p$-dioxin exhibits altered expressions of growth regulatory factors," Carcinogenesis, vol. 20, no. 1, pp. 13-18, 1999.

[10] T. Negishi, Y. Kato, O. Ooneda, et al., "Effects of aryl hydrocarbon receptor signaling on the modulation of Th1/Th2 balance," Journal of Immunology, vol. 175, no. 11, pp. 73487356, 2005.

[11] M. S. Denison, A. Pandini, S. R. Nagy, E. P. Baldwin, and L. Bonati, "Ligand binding and activation of the Ah receptor," Chemico-Biological Interactions, vol. 141, no. 1-2, pp. 3-24, 2002.

[12] Y.-Z. Gu, J. B. Hogenesch, and C. A. Bradfield, "The PAS superfamily: sensors of environmental and developmental signals," Annual Review of Pharmacology and Toxicology, vol. 40, pp. 519-561, 2000.

[13] B. L. Taylor and I. B. Zhulin, "PAS domains: internal sensors of oxygen, redox potential, and light," Microbiology and Molecular Biology Reviews, vol. 63, no. 2, pp. 479-506, 1999.

[14] R. Villalobos-Molina, F. G. Vázquez-Cuevas, J. J. LópezGuerrero, et al., "Vascular $\alpha 1 \mathrm{D}$-adrenoceptors are overexpressed in aorta of the aryl hydrocarbon receptor null mouse: role of increased angiotensin II," Autonomic and Autacoid Pharmacology, vol. 28, no. 2-3, pp. 61-67, 2008.

[15] M. Rodríguez-Sosa, G. Elizondo, R. M. López-Durán, I. Rivera, F. J. Gonzalez, and L. Vega, "Over-production of IFN- $\gamma$ and IL-12 in AhR-null mice," FEBS Letters, vol. 579, no. 28, pp. 6403-6410, 2005.

[16] P. Fernandez-Salguero, T. Pineau, D. M. Hilbert, et al., "Immune system impairment and hepatic fibrosis in mice lacking the dioxin-binding Ah receptor," Science, vol. 268, no. 5211, pp. 722-726, 1995. 
[17] C. Esser, A. Rannug, and B. Stockinger, "The aryl hydrocarbon receptor in immunity," Trends in Immunology, vol. 30, no. 9, pp. 447-454, 2009.

[18] B. Jux, S. Kadow, and C. Esser, "Langerhans cell maturation and contact hypersensitivity are impaired in aryl hydrocarbon receptor-null mice," Journal of Immunology, vol. 182, no. 11, pp. 6709-6717, 2009.

[19] M. Veldhoen, K. Hirota, A. M. Westendorf, et al., "The aryl hydrocarbon receptor links TH17-cell-mediated autoimmunity to environmental toxins," Nature, vol. 453, no. 7191, pp. 106-109, 2008.

[20] B. P. Lawrence and B. A. Vorderstrasse, "Activation of the aryl hydrocarbon receptor diminishes the memory response to homotypic influenza virus infection but does not impair host resistance," Toxicological Sciences, vol. 79, no. 2, pp. 304-314, 2004.

[21] B. A. Vorderstrasse and B. P. Lawrence, "Protection against lethal challenge with Streptococcus pneumoniae is conferred by aryl hydrocarbon receptor activation but is not associated with an enhanced inflammatory response," Infection and Immunity, vol. 74, no. 10, pp. 5679-5686, 2006.

[22] L. Z. Shi, N. G. Faith, Y. Nakayama, M. Suresh, H. Steinberg, and C. J. Czuprynski, "The aryl hydrocarbon receptor is required for optimal resistance to Listeria monocytogenes infection in mice," Journal of Immunology, vol. 179, no. 10, pp. 6952-6962, 2007.

[23] E. Y. Denkers and R. T. Gazzinelli, "Regulation and function of T-cell-mediated immunity during Toxoplasma gondii infection," Clinical Microbiology Reviews, vol. 11, no. 4, pp. 569$588,1998$.

[24] L. A. Lieberman and C. A. Hunter, "The role of cytokines and their signaling pathways in the regulation of immunity to Toxoplasma gondii," International Reviews of Immunology, vol. 21, no. 4-5, pp. 373-403, 2002.

[25] T. Scharton-Kersten, E. Y. Denkers, R. Gazzinelli, and A. Sher, "Role of IL12 in induction of cell-mediated immunity to Toxoplasma gondii," Research in Immunology, vol. 146, no. 78, pp. 539-545, 1995.

[26] G. S. Yap and A. Sher, "Cell-mediated immunity to Toxoplasma gondii: initiation, regulation and effector function," Immunobiology, vol. 201, no. 2, pp. 240-247, 1999.

[27] A. Sher, I. P. Oswald, S. Hieny, and R. T. Gazzinelli, "Toxoplasma gondii induces a T-independent IFN- $\gamma$ response in natural killer cells that requires both adherent accessory cells and tumor necrosis factor- $\alpha$," Journal of Immunology, vol. 150, no. 9, pp. 3982-3989, 1993.

[28] R. T. Gazzinelli, F. T. Hakim, S. Hieny, G. M. Shearer, and A. Sher, "Synergistic role of $\mathrm{CD}^{+}$and $\mathrm{CD}^{+} \mathrm{T}$ lymphocytes in IFN- $\gamma$ production and protective immunity induced by an attenuated Toxoplasma gondii vaccine," Journal of Immunology, vol. 146, no. 1, pp. 286-292, 1991.

[29] M. Flores, R. Saavedra, R. Bautista, et al., "Macrophage migration inhibitory factor (MIF) is critical for the host resistance against Toxoplasma gondii," FASEB Journal, vol. 22, no. 10, pp. 3661-3671, 2008.

[30] T. M. Scharton-Kersten, G. Yap, J. Magram, and A. Sher, "Inducible nitric oxide is essential for host control of persistent but not acute infection with the intracellular pathogen Toxoplasma gondii," Journal of Experimental Medicine, vol. 185, no. 7, pp. 1261-1273, 1997.

[31] R. T. Gazzinelli, S. Hieny, T. A. Wynn, S. Wolf, and A. Sher, "Interleukin 12 is required for the T-lymphocyte-independent induction of interferon $\gamma$ by an intracellular parasite and induces resistance in T-cell-deficient hosts," Proceedings of the
National Academy of Sciences of the United States of America, vol. 90, no. 13, pp. 6115-6119, 1993.

[32] T. Fukao, D. M. Frucht, G. Yap, M. Gadina, J. J. O’Shea, and S. Koyasu, "Inducible expression of Stat 4 in dendritic cells and macrophages and its critical role in innate and adaptive immune responses," Journal of Immunology, vol. 166, no. 7, pp. 4446-4455, 2001.

[33] J. Aliberti, S. Hieny, C. Reis e Sousa, C. N. Serhan, and A. Sher, "Lipoxin-mediated inhibition of IL-12 production by DCs: a mechanism for regulation of microbial immunity," Nature Immunology, vol. 3, no. 1, pp. 76-82, 2002.

[34] R. Saavedra, R. Leyva, E. P. Tenorio, et al., "CpG-containing ODN has a limited role in the protection against Toxoplasma gondii," Parasite Immunology, vol. 26, no. 2, pp. 67-73, 2004.

[35] W. L. Homan, M. Vercammen, J. de Braekeleer, and H. Verschueren, "Identification of a 200- to 300-fold repetitive 529 bp DNA fragment in Toxoplasma gondii, and its use for diagnostic and quantitative PCR," International Journal for Parasitology, vol. 30, no. 1, pp. 69-75, 2000.

[36] G. C. Ulett, N. Ketheesan, and R. G. Hirst, "Cytokine gene expression in innately susceptible $\mathrm{BALB} / \mathrm{c}$ mice and relatively resistant C57BL/6 mice during infection with virulent Burkholderia pseudomallei," Infection and Immunity, vol. 68, no. 4, pp. 2034-2042, 2000.

[37] L. I. Terrazas, D. Montero, C. A. Terrazas, J. L. Reyes, and M. Rodríguez-Sosa, "Role of the programmed death-1 pathway in the suppressive activity of alternatively activated macrophages in experimental cysticercosis," International Journal for Parasitology, vol. 35, no. 13, pp. 1349-1358, 2005.

[38] Q. Tong, G. Dalgin, H. Xu, C.-N. Ting, J. M. Leiden, and G. S. Hotamisligil, "Function of GATA transcription factors in preadipocyte-adipocyte transition," Science, vol. 290, no. 5489, pp. 134-138, 2000.

[39] G. Bonizzi, J. Piette, M.-P. Merville, and V. Bours, "Distinct signal transduction pathways mediate nuclear factor- $\kappa \mathrm{B}$ induction by IL- $1 \beta$ in epithelial and lymphoid cells," Journal of Immunology, vol. 159, no. 11, pp. 5264-5272, 1997.

[40] M. Renshaw, J. Rockwell, C. Engleman, A. Gewirtz, J. Katz, and S. Sambhara, "Cutting edge: impaired toll-like receptor expression and function in aging," Journal of Immunology, vol. 169, no. 9, pp. 4697-4701, 2002.

[41] M. Rodríguez-Sosa, L. E. Rosas, J. R. David, R. Bojalil, A. R. Satoskar, and L. I. Terrazas, "Macrophage migration inhibitory factor plays a critical role in mediating protection against the helminth parasite Taenia crassiceps," Infection and Immunity, vol. 71, no. 3, pp. 1247-1254, 2003.

[42] J. L. Reyes, L. I. Terrazas, B. Espinoza, et al., "Macrophage migration inhibitory factor contributes to host defense against acute Trypanosoma cruzi infection," Infection and Immunity, vol. 74, no. 6, pp. 3170-3179, 2006.

[43] D. L. Granger, R. R. Taintor, K. S. Boockvar, and J. B. Hibbs Jr., "Measurement of nitrate and nitrite in biological samples using nitrate reductase and Griess reaction," Methods in Enzymology, vol. 268, pp. 142-151, 1996.

[44] P. Migliorini, G. Corradin, and S. B. Corradin, "Macrophage $\mathrm{NO}_{2}{ }^{-}$production as a sensitive and rapid assay for the quantitation of murine IFN- $\gamma$," Journal of Immunological Methods, vol. 139, no. 1, pp. 107-114, 1991.

[45] G. Trinchieri, "Interleukin-12: a cytokine at the interface of inflammation and immunity," Advances in Immunology, vol. 70, pp. 83-243, 1998.

[46] G. Yap, M. Pesin, and A. Sher, "Cutting edge: IL-12 is required for the maintenance of IFN- $\gamma$ production in T cells mediating chronic resistance to the intracellular pathogen, Toxoplasma 
gondii," Journal of Immunology, vol. 165, no. 2, pp. 628-631, 2000.

[47] J. Aliberti, C. Reis e Sousa, M. Schito, et al., "CCR5 provides a signal for microbial induced production of IL-12 by CD $8 \alpha^{+}$ dendritic cells," Nature Immunology, vol. 1, no. 1, pp. 83-87, 2000.

[48] F. S. Machado, J. E. Johndrow, L. Esper, et al., "Antiinflammatory actions of lipoxin A4 and aspirin-triggered lipoxin are SOCS-2 dependent," Nature Medicine, vol. 12, no. 3, pp. 330-334, 2006.

[49] B. A. Vorderstrasse, J. A. Cundiff, and B. P. Lawrence, "A dose-response study of the effects of prenatal and lactational exposure to TCDD on the immune response to influenza A virus," Journal of Toxicology and Environmental Health A, vol. 69, no. 6, pp. 445-463, 2006.

[50] Y. Suzuki, M. A. Orellana, R. D. Schreiber, and J. S. Remington, "Interferon- $\gamma$ : the major mediator of resistance against Toxoplasma gondii," Science, vol. 240, no. 4851, pp. 516-518, 1988.

[51] U. Gross, O. Keksel, and M. L. Dardé, "Value of detecting immunoglobulin E antibodies for the serological diagnosis of Toxoplasma gondii infection," Clinical and Diagnostic Laboratory Immunology, vol. 4, no. 3, pp. 247-251, 1997.

[52] J. Matowicka-Karna, V. Dymicka-Piekarska, and H. Kemona, "Does Toxoplasma gondii infection affect the levels of IgE and cytokines (IL-5, IL-6, IL-10, IL-12, and TNF-alpha)?” Clinical and Developmental Immunology, vol. 2009, Article ID 374696, 4 pages, 2009.

[53] I. A. Khan, J. D. Schwartzman, T. Matsuura, and L. H. Kasper, "A dichotomous role for nitric oxide during acute Toxoplasma gondii infection in mice," Proceedings of the National Academy of Sciences of the United States of America, vol. 94, no. 25, pp. 13955-13960, 1997.

[54] Y. Suzuki, A. Sher, G. Yap, et al., "IL-10 is required for prevention of necrosis in the small intestine and mortality in both genetically resistant BALB/c and susceptible C57BL/6 mice following peroral infection with Toxoplasma gondii," Journal of Immunology, vol. 164, no. 10, pp. 5375-5382, 2000.

[55] G. Elizondo, P. Fernandez-Salguero, M. S. Sheikh, et al., "Altered cell cycle control at the $\mathrm{G}_{2} / \mathrm{M}$ phases in aryl hydrocarbon receptor-null embryo fibroblast," Molecular Pharmacology, vol. 57, no. 5, pp. 1056-1063, 2000.

[56] C. J. Funatake, N. B. Marshall, L. B. Steppan, D. V. Mourich, and N. I. Kerkvliet, "Cutting edge: activation of the aryl hydrocarbon receptor by 2,3,7,8-tetrachlorodibenzo-p-dioxin generates a population of $\mathrm{CD} 4^{+} \mathrm{CD} 25^{+}$cells with characteristics of regulatory T cells," Journal of Immunology, vol. 175, no. 7, pp. 4184-4188, 2005.

[57] F. Yarovinsky and A. Sher, "Toll-like receptor recognition of Toxoplasma gondii," International Journal for Parasitology, vol. 36, no. 3, pp. 255-259, 2006.

[58] H.-S. Mun, F. Aosai, K. Norose, et al., "TLR2 as an essential molecule for protective immunity against Toxoplasma gondii infection," International Immunology, vol. 15, no. 9, pp. 10811087, 2003.

[59] S. Chamorro, J. J. García-Vallejo, W. W. Unger, et al., "TLR triggering on tolerogenic dendritic cells results in TLR2 upregulation and a reduced proinflammatory immune program," Journal of Immunology, vol. 183, no. 5, pp. 2984-2994, 2009.

[60] M. G. Netea, R. Sutmuller, C. Hermann, et al., "Toll-like receptor 2 suppresses immunity against Candida albicans through induction of IL-10 and regulatory T cells," Journal of Immunology, vol. 172, no. 6, pp. 3712-3718, 2004.
[61] Y. Yanagawa and K. Onoé, "Enhanced IL-10 production by TLR4- and TLR2-primed dendritic cells upon TLR restimulation," Journal of Immunology, vol. 178, no. 10, pp. 6173-6180, 2007.

[62] C. M. Schaldach, J. Riby, and L. F. Bjeldanes, "Lipoxin A4: a new class of ligand for the Ah receptor," Biochemistry, vol. 38, no. 23, pp. 7594-7600, 1999.

[63] J. Aliberti, C. Serhan, and A. Sher, "Parasite-induced lipoxin A4 is an endogenous regulator of IL-12 production and immunopathology in Toxoplasma gondii infection," Journal of Experimental Medicine, vol. 196, no. 9, pp. 1253-1262, 2002. 

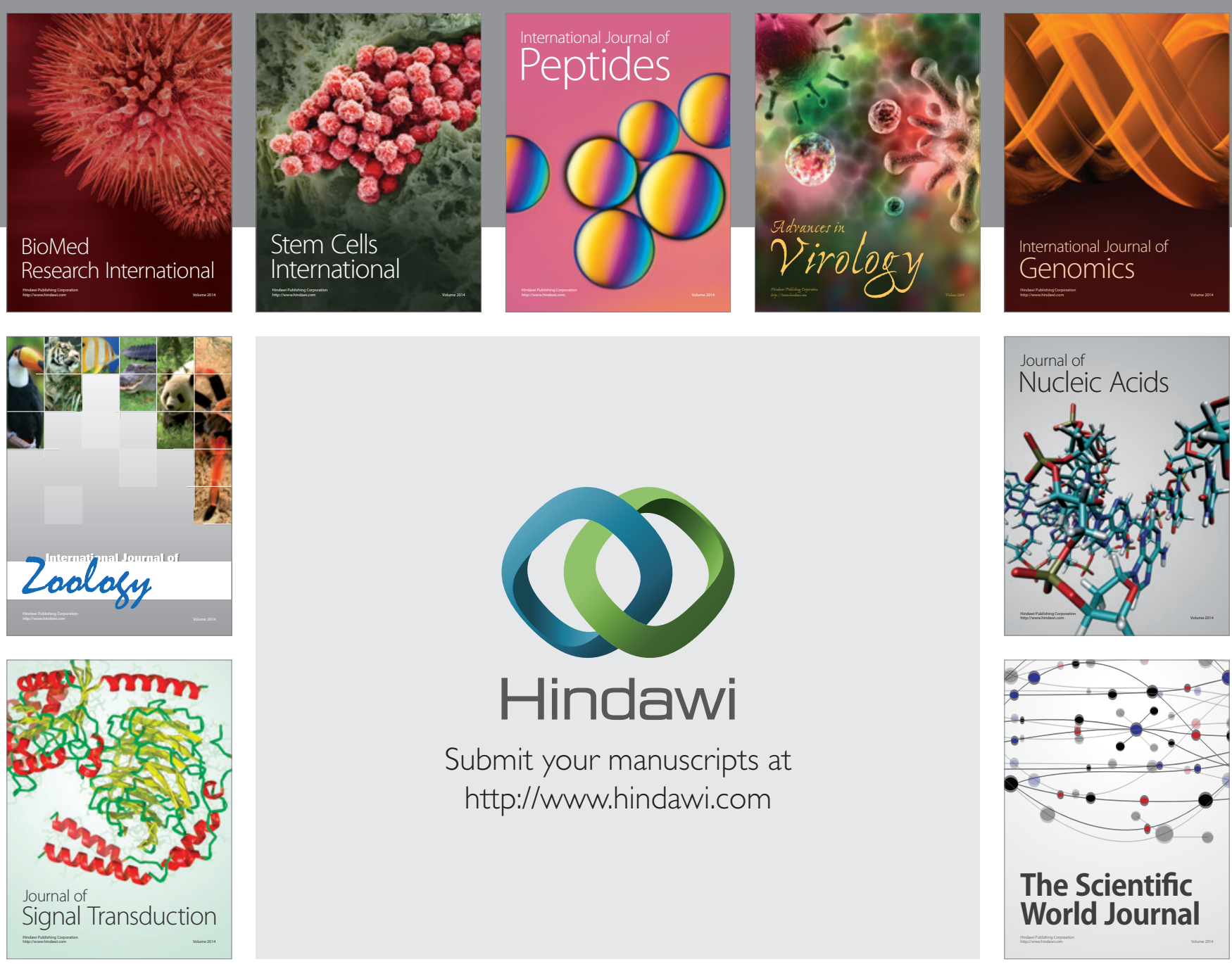

Submit your manuscripts at

http://www.hindawi.com
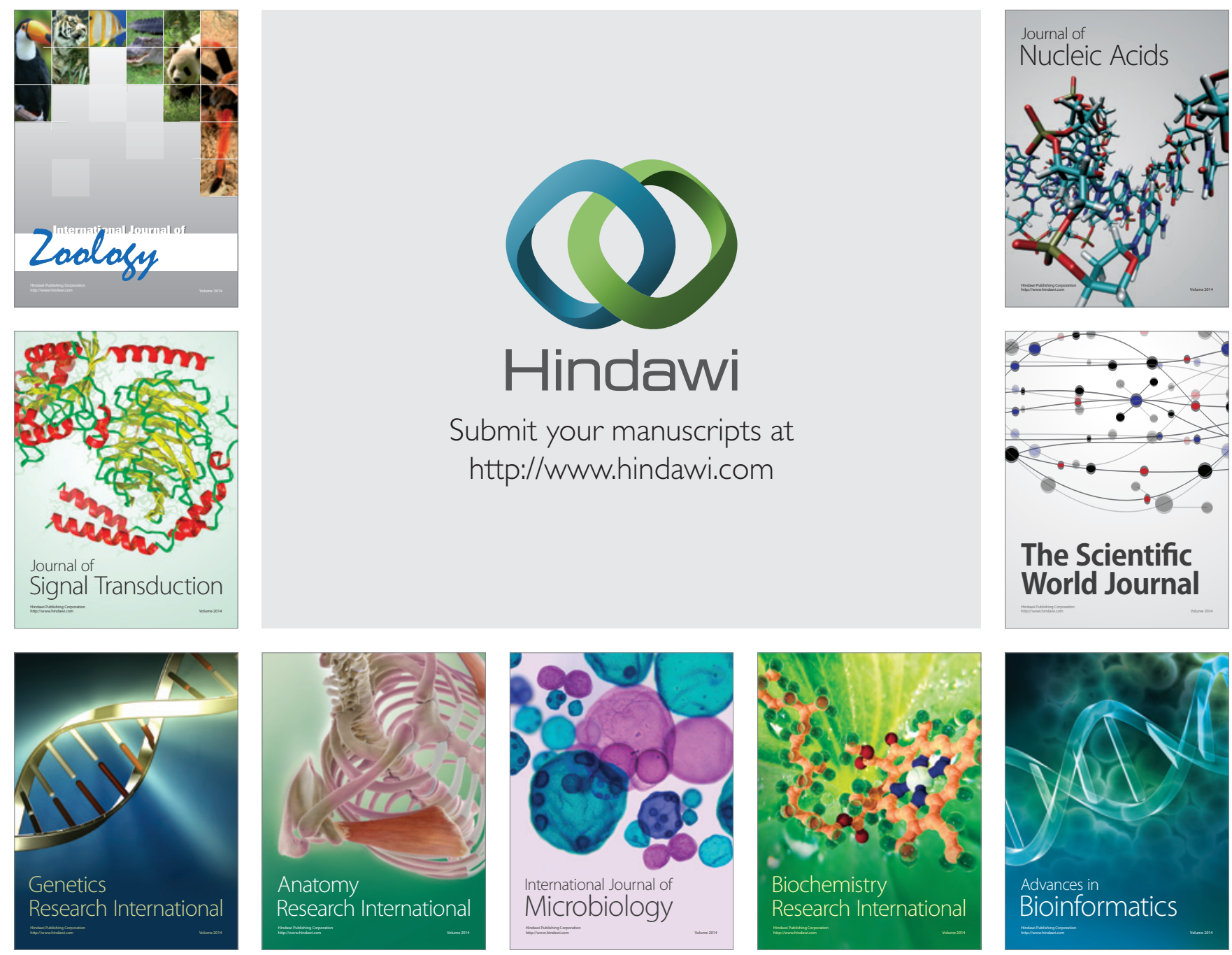

The Scientific World Journal
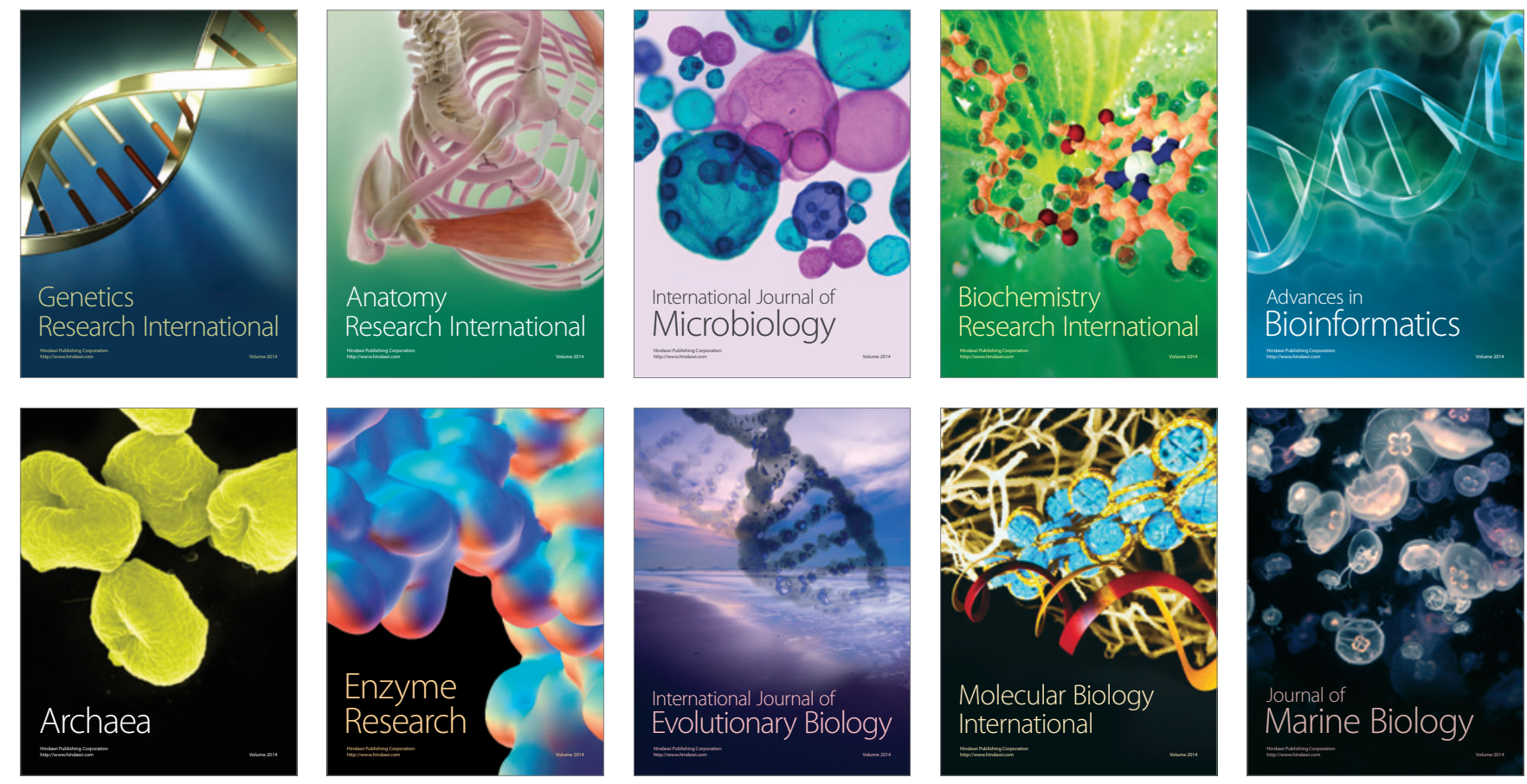